\title{
An essential function for autocrine Hedgehog signaling in epithelial proliferation and differentiation in the trachea
}

Wenguang Yin ${ }^{1,2,3^{*}}$, Andreas Liontos ${ }^{5,6}$, Janine Koepke ${ }^{1}$, Maroua Ghoul ${ }^{1}$, Luciana

Mazzocchi ${ }^{1}$, Xinyuan $\mathrm{Liu}^{2}$, Chunyan $\mathrm{Lu}^{2}$, Haoyu $\mathrm{Wu}^{2}$, Athanasios Fysikopoulos ${ }^{1}$, Alexandros Sountoulidis $^{5,6}$, Werner Seeger ${ }^{1,4}$, Clemens Ruppert ${ }^{1}$, Andreas Günther ${ }^{1}$, Didier Y.R. Stainier ${ }^{3}$ and Christos Samakovlis ${ }^{1,4,5,6^{*}}$

${ }^{1}$ Cardio-Pulmonary Institute, Member of the German Center for Lung Research (DZL), University of Giessen and Marburg Lung Center (UGMLC), Justus Liebig University of Giessen, Giessen, 35392, Germany.

${ }^{2}$ State Key Laboratory of Respiratory Disease, National Clinical Research Center for Respiratory Disease, Guangzhou Institute of Respiratory Health, the First Affiliated Hospital of Guangzhou Medical University, Guangzhou, Guangdong, 510182, P.R. China.

${ }^{3}$ Department of Developmental Genetics, Max Planck Institute for Heart and Lung Research, Member of the German Center for Lung Research (DZL), Bad Nauheim, 61231, Germany.

${ }^{4}$ Department of Lung Development and Remodeling, Max Planck Institute for Heart and Lung Research, Bad Nauheim, Germany.

${ }^{5}$ Department of Molecular Biosciences, The Wenner-Gren Institute, Stockholm University, S10691, Stockholm, Sweden.

${ }^{6}$ Science for Life Laboratory, Stockholm University, Solna, Sweden.

Correspondence and requests for materials should be addressed to Wenguang Yin (yin_wenguang@gzhmu.edu.cn) or Christos Samakovlis (Christos.Samakovlis@ su.se) 


\begin{abstract}
Abstract

The tracheal epithelium is a primary target for pulmonary diseases as it provides a conduit for air flow between the environment and the lung lobes. The cellular and molecular mechanisms underlying airway epithelial cell proliferation and differentiation remain poorly understood. Hedgehog $(\mathrm{Hh})$ signaling orchestrates communication between epithelial and mesenchymal cells in the lung, where it modulates stromal cell proliferation, differentiation and signaling back to the epithelium. Here, we reveal a new, autocrine function of Hh signaling in airway epithelial cells. Epithelial cell depletion of the ligand Sonic hedgehog (SHH) or its effector Smoothened (SMO) causes defects in both epithelial cell proliferation and differentiation. In cultured primary human airway epithelial cells, Hh signaling inhibition also hampers cell proliferation and differentiation. Epithelial Hh function is mediated, at least in part, through transcriptional activation as Hh signaling inhibition leads to downregulation of cell-type specific transcription factor genes in both the mouse trachea and human airway epithelial cells. These results provide new insights into the role of $\mathrm{Hh}$ signaling in epithelial cell proliferation and differentiation during airway development.
\end{abstract}

\title{
KEY WORDS: Sonic hedgehog; Smoothened; trachea; tracheomalacia; airway
} epithelial cells 


\section{INTRODUCTION}

Hedgehog $(\mathrm{Hh})$ signaling regulates tissue patterning and cell differentiation in most animals. In mammals, there are three Hh ligands, desert hedgehog (DHH), indian hedgehog (IHH) and sonic hedgehog $(\mathrm{SHH})$. Hh signaling has been investigated in depth during limb formation (Riddle et al., 1993), endodermal organ development (Sala et al., 2011; Bellusci et al., 1997), and cell differentiation in the neural tube (Ericson et al., 1995).

In the lung epithelium, SHH is a highly expressed ligand coordinating both organ formation and homeostasis (Sala et al., 2011; Bellusci et al., 1997; Peng et al., 2015). Epithelial SHH activates the transmembrane protein Smoothened (SMO) in mesenchymal cells leading to nuclear translocation and activation of GLI transcription factors. The activation of $\mathrm{Hh}$ signaling in the signal-receiving cells depends on the negative regulators PTCH1 and HHIP, whose transcription is in turn activated by GLI proteins, creating a tightly regulated negative feedback loop (Wang et al., 2018; Kugler et al., 2015). During lung development, the activation balance of Gli1, Gli2 and Gli3 controls cell proliferation and differentiation of mesenchymal airway smooth muscle cells (Li et al., 2004) and endothelial cells (Li et al., 2004; Miller et al., 2004). In the mesenchyme, Hh signaling activation also controls the expression of genes encoding signals like FGF10 or BMP4 (Weaver et al., 2003), which become activated or restricted in highly localized domains to shape epithelial branching and morphogenesis (Pepicelli et al., 1998; Herriges et al., 2015). In adult lungs, Hh signaling is activated upon injury (Watkins et al., 2003) and recent studies have shown that activation of Hh signaling in $\mathrm{Gli1}^{+}$mesenchymal cells maintains quiescence in club cells (Peng et al., 2015). In the alveolar compartment, asymmetric Hedgehog signaling activation in the distal mesenchymal cells marked by Gli2 and Pdgfr $\alpha$ expression controls alveolar epithelial cell proliferation (Wang et al., 2018). Ectopic activation of Hh signaling in the distal mesenchyme leads to emphysema-like phenotypes (Wang et al., 2018). These results highlight a central function for Hh signaling in adult lung homeostasis. In parallel, several genome-wide association studies (GWAS) have identified polymorphisms in genes encoding Hh signaling components in cohorts of asthma and COPD patients implicating Hh signaling in chronic lung disease initiation or progression (Kugler et al., 2015; Wang et al., 2019). Overall, genetic studies of Hh signaling in the mouse embryonic and adult lungs have focused on the paracrine role of epithelial SHH in controlling the patterning of the mesenchyme. Mesenchymal cells respond to SHH by the restricted activation of distinct programs that in turn, guide epithelial morphogenesis and tissue repair responses in the adult. Although the paracrine functions of SHH are instrumental in the lung, its potential autocrine function in respiratory tract development has not been formally investigated. Recent pharmacological evidence has suggested a role of SHH in the proliferation and differentiation of cultured human primary nasal epithelial (HNE) cells (Belgacemi et al., 2020), but the role of epithelial Hh signaling in the lung remains elusive.

The tracheal tube consists of endoderm-derived epithelium surrounded by mesoderm-derived cartilage, connective tissue, and smooth muscle (Brand-Saberi et al., 2014). The tracheal epithelium is composed of several cell types including basal progenitor cells, ciliated cells, club cells, goblet cells, neuroendocrine cells, tuft cells and ionocytes (Montoro et al., 2019; 
Plasschaert et al., 2018). Like the lung airways, tracheal tube formation depends on complex epithelial-mesenchymal interactions (Sala et al., 2011; Hines et al., 2013; Snowball et al., 2015; Gerhardt et al., 2018) that orchestrate cellular proliferation (Snowball et al., 2015) and differentiation (Gerhardt et al., 2018). During embryonic development, inactivation of $\mathrm{Hh}$ signaling impairs tracheal cartilage formation by reducing $\mathrm{SOX}^{+}$chondrocyte proliferation (Park et al., 2010), differentiation (Park et al., 2010) and condensation (Yin et al., 2018). This process involves the interplay of SHH emanating from the tracheal epithelium and FGF10 from the mesenchyme (Sala et al., 2011). A recent genetic study in pediatric patients associated Hh signaling with tracheal ring deformity characterized by complete cartilaginous rings surrounding the trachea and tracheal stenosis (Sinner et al., 2019).

Here, we investigate the potential role of Hh signaling in tracheal epithelial cells. We first show that Hh signaling components are dynamically expressed in the tracheal epithelium and mesenchyme. Conditional Shh inactivation in Nkx2.1-expressing epithelial cells led to early postnatal lethality accompanied by respiratory defects. The tracheal cartilage rings were discontinuous and the tracheal tube collapsed. Epithelial cell proliferation and the number of differentiated secretory and multiciliated cells were reduced in the Shh mutant trachea. Inactivation of the transmembrane protein Smo or expression of a dominant active form of Smo in the lung endoderm caused opposite defects in tracheal epithelial cell proliferation and differentiation arguing for an autocrine role of Hh signaling in directly promoting proliferation and differentiation in the tracheal epithelium. We used an in vitro air-liquid interface (ALI) differentiation model of primary human bronchial cells to test whether the autocrine role of $\mathrm{Hh}$ signaling functions in isolated human epithelial cells. Chemical inhibition of SMO, or GLI, led to defects in epithelial cell proliferation and differentiation arguing for an epithelial cell-autonomous function of Hh signaling in human bronchial cells as well. Our results reveal a new autocrine function of $\mathrm{Hh}$ signaling in addition to its previously characterized paracrine roles in respiratory organ development and prompt further investigations of epithelial Smo-mediated Hh signaling in lung epithelial cells during embryonic development and lung disease progression. 


\section{RESULTS}

\section{Epithelial deletion of Shh results in tracheal tube formation defects}

To examine the spatiotemporal mRNA expression of Hh signaling components in the developing trachea, we performed multiplex fluorescence in situ hybridizations using SCRINSHOT (Single Cell Resolution IN Situ Hybridization On Tissues) during embryonic stages (Sountoulidis et al., 2020). We examined the cellular colocalization of Shh, Smo, Patched 1 (Ptch1), Patched 2 (Ptch2), Hedgehog interacting protein (Hhip), Gli1, Gli2 and Gli3 mRNAs in epithelial and mesenchymal cells from E13.5 to E15.5 (Fig. 1a-b). To mark epithelial cells, we used probes against the $C d h 1$ and Trp63 mRNAs. Shh was expressed in the epithelium and Hhip in the mesenchyme and both displayed reduction in expression levels from E13.5 to E15.5 (Fig. 1a, b). The Hh signaling transducer gene Smo was expressed in both epithelial and mesenchymal cells including putative chondroblasts (Fig. 1a, b and Supplementary Fig. 1). Similarly, the Hh signaling transcription factor genes (Gli1, Gli2 and Gli3) and transmembrane receptor genes (Ptch1 and Ptch2) were detected in both epithelial and mesenchymal cells and displayed higher expression levels at E13.5 compared to E15.5 (Fig. 1a, b). We also examined Shh, Smo, Gli1 and Gli2 mRNA levels in whole tracheal extracts by quantitative reverse transcription PCR (RT-qPCR). Shh, Smo, Glil and Gli2 mRNAs were detectable as early as E12.5 and became gradually reduced until E18.5 (Supplementary Fig. 2a-d). Smo mRNA levels did not dramatically change possibly due to mesenchymal expression. These data show dynamic expression of Hh signaling components in the developing trachea and suggest that Hh signaling may operate in both epithelial and mesenchymal tracheal cell development.

To identify single embryonic cells that express Hh signaling components and relate their expression with known cell types of the trachea, we used publicly available single cell transcriptomic data, from E12.5 to E18.5 stage wild-type (WT) tracheal epithelial cells (Kiyokawa et al., 2021). We projected the expression of a panel of Hh signaling components on these data (Supplementary Fig. 3) and kept the cell type classification of the published study. We found Shh and Smo to be highly expressed in embryonic tracheal epithelial cells and the majority of the embryonic cells were positive for $S h h$ or Smo. There were also a few embryonic cells that co-expressed both the ligand and the transducer. At later stages (E16.5 and E18.5), when known cell type markers initiate their expression, we detected the expression of Shh or Smo in a few ciliated, club and basal cells (Fig. 1c). Moreover, coexpression of Shh and Smo was only detected in rare club or basal cells but not in ciliated cells. The number of epithelial cells expressing Shh signaling components increased up to E15.5 and was reduced in later stages when cell type specific markers were expressed (Fig. 1d). Recently, Ihh was also reported to be expressed by alveolar epithelial cells (Nikolić et al., 2017), but at comparatively very low levels and only in a few embryonic tracheal epithelial cells (Supplementary Fig. 3d). These data suggest an autocrine function of Hh signaling on epithelial cells in early stages of trachea development (up to stage E16). We conclude that epithelial Hh signaling is activated in the trachea and hypothesize that the autocrine function of $\mathrm{Hh}$ signaling on the tracheal epithelium could occur in two ways, either 
in a cell-autonomous autocrine fashion or in a paracrine fashion between epithelial cells of different types.

Shh mutants exhibit defects in tracheal cartilage formation during embryonic stages (Park et al., 2010; Yin et al., 2018). We thus hypothesized that epithelial deletion of Shh might cause tracheomalacia with respiratory distress. To inactivate $S h h$ expression specifically in the tracheal epithelium, we used a BAC transgenic mouse line where Cre recombinase is expressed under the control of $N k x 2.1$ control elements $\left(N k x 2.1^{C r e}\right.$ ) (Xu et al., 2017). The recombination efficiency of $N k x 2.1^{C r e}$ in the trachea and lungs has been previously characterized in $N k x 2.1^{C r e}$;ROSA26R-LacZ embryos (Sala et al., 2011; Tiozzo et al., 2009). In these experiments, LacZ activity was detected in the lung epithelium as early as E10.5 and the pattern of LacZ activity was nearly homogeneous throughout the tracheal epithelium at E13.5 (Sala et al., 2011; Tiozzo et al., 2009). Thus, the $N k x 2.1^{\text {Cre }}$ strain induces recombination in tracheal epithelial cells with high efficiency. We further evaluated the recombination efficiency of the Shhflox allele, by RT-qPCR for Shh mRNA expression in WT embryos and in $N k x 2.1^{C r e}$; Shh ${ }^{\text {floxflox }}$ (ShhCKO) mutants. We observed a strong reduction of Shh mRNA levels in both E11.5 and E18.5 stages in ShhCKO tracheae compared with controls (Supplementary Fig. 4). ShhCKO mice displayed cyanosis (Fig. 1e), neonatal respiratory distress (Fig. 1f and Supplementary Video), and died within 24 hours of birth. These mutants were born in the expected Mendelian ratio with a collapsed tracheal lumen (Fig. 1g, h), and fractured cartilage rings instead of the intact ventrolateral cartilage rings seen in control siblings (Fig. 1i, j), indicating that epithelial inactivation of Shh does not cause embryonic lethality. ShhCKO mice exhibited no trachea-esophageal fistula at E17.5.

Although Shh mRNA levels in E11.5 ShhCKO lungs were already severely reduced, the lack of fistula may suggest that Shh inactivation in this strain occurs after the separation of the trachea from the esophagus (Supplementary Fig. 5a, b). To test for a role of Shh in lung development, we analyzed the embryonic lungs at E17.5. As expected, ShhCKO animals also exhibited pulmonary hemorrhage (Fig. 1k, l) and cysts (Fig. 1k, m), mainly in distal regions compared with controls (Miller et al.,2004). These data indicate that the mutants die from compromised respiratory function due to defective formation of the tracheal tube with high airflow resistance limiting breathing frequency and respiratory air sacs additionally impacting gas exchange.

\section{Epithelial cell differentiation and proliferation defects in the ShhCKO trachea}

Sonic Hedgehog signaling controls epithelial differentiation in endodermal organs including the esophagus and thymus (Freestone et al., 2003; van Dop et al., 2013; Saldaña et al., 2016). To test for a possible role of Shh signaling in tracheal epithelial cell differentiation, we performed immunostaining for characteristic markers of major tracheal epithelial cell types. FOXJ1, a ciliated cell marker, is expressed in the trachea around E15.5 (Stauber et al., 2017). We observed several FOXJ1 ${ }^{+}$but no acetylated alpha-tubulin ${ }^{+}$cells in the WT tracheal epithelium at E15.5 (Supplementary Fig. 6a, b). Acetylated alpha-tubulin ${ }^{+}$ciliated cells were detected at E16.5 (Supplementary Fig. 6b), indicating that mature ciliated cells first appear in the trachea between E15.5 and E16.5. From E18.5, an even distribution of acetylated alpha- 
tubulin $^{+}$ciliated cells was observed in the tracheal epithelium (Supplementary Fig. 6b). Interestingly, ShhCKO animals at E18.5 exhibited reduced FOXJ1+ ciliated cells (Fig. 2a, b) with decreased Foxj1 mRNA levels compared to controls (Fig. 2c). Consistently, the relative number of mature ciliated cells expressing acetylated alpha-tubulin (Fig. 2d, e), and the overall Tubb4b mRNA levels (Fig. 2c), were also reduced in ShhCKO animals. Next, we examined markers of club cell maturation in the mutant epithelium. SCGB1A1, a mature club cell marker, was readily detected in the WT tracheal epithelium at E18.5 (Supplementary Fig. 6c). These SCGB1A1+ cells were distributed evenly in the apical epithelial surface and expressed variable SCGB1A1 levels at this stage of development (Supplementary Fig. 6c). ShhCKO tracheal sections from E18.5 embryos exhibited fewer SCGB1A1 ${ }^{+}$club cells (Fig. 2f, g) and decreased Scgblal mRNA levels compared with controls (Fig. 2c). Intriguingly, the earlier secretory club cell fate markers SCGB3A2 and SCGB3A1 (Guha et al., 2012; Reynolds et al., 2002), which were detected in the WT trachea already at E17.5 (Supplementary Fig. 6d, e), exhibited a similar distribution in ShhCKO and WT tracheae (Supplementary Fig. 7a-d). The overall levels of Scgb3a2 and Scgb3al mRNA in the mutant trachea were also similar to controls (Supplementary Fig. 7e). These results indicate that Hh signaling is required for the progression but not the initiation of the secretory club cell differentiation program. To further examine epithelial differentiation defects in the trachea at a postnatal stage, we performed immunostaining in tissue sections at P0. ShhCKO tracheae exhibited persistently reduced numbers of acetylated alpha-tubulin ${ }^{+}$ciliated cells (Supplementary Fig. 8a, b) and of SCGB1A1+ club cells (Supplementary Fig. 8a, c) compared with controls, arguing that these defects are not due to a general delay of differentiation. Since the transcription factors FOXP1 and FOXP4 cooperatively modulate club cell differentiation in the airways (Li et al., 2012), we examined for changes in Foxp1 and Foxp4 expression. ShhCKO tracheae exhibited reduced Foxpl expression (Fig. 2c), suggesting that Foxpl is a potential target of Hh signaling during club cell development.

Hh signaling has been reported to modulate cell proliferation in several contexts (Berman et al., 2003; Thayer et al., 2003; van den Brink et al., 2004; Merchant et al., 2010; Plaisant et al., 2011; Gagné-Sansfaçon et al., 2014; Raleigh et al., 2018). We thus tested whether epithelial deletion of $S h h$ might lead to tracheal epithelial cell proliferation defects. We examined epithelial cell proliferation first by immunostaining for Ki67, a cell cycle marker, and found that $S h h C K O$ tracheae exhibited a reduced number of $\mathrm{Ki}^{+} 7^{+}$cells in the CDH1 marked epithelium compared with controls (Fig. 2h, i). Next, we performed an EdU incorporation assay to assess cells that had entered S-phase during the labeling period. After an ex vivo, 21 hours long EdU treatment, ShhCKO tracheae displayed fewer EdU ${ }^{+}$cells in their epithelium (Fig. 2j, k), indicating that Hedgehog inactivation compromises cell cycle entry. In a more detailed analysis, we observed a reduced number of $\mathrm{Ki}^{+} 7^{+} \mathrm{SCGB} 1 \mathrm{~A} 1^{+}$cells (Fig. 21, m), but a similar number of PDPN ${ }^{+}$(Supplementary Fig. 9a, b) and Ki67 ${ }^{+}$PDPN $^{+}$ basal cells (Supplementary Fig. 9a, c) in ShhCKO tracheae compared with controls. Interestingly, $\mathrm{Sh} h \mathrm{CKO}$ tracheae exhibited increased ratios of $\mathrm{KRT}^{+}$basal cells to acetylated alpha-tubulin $^{+}$ciliated cells and to SCGB1A1 ${ }^{+}$club cells compared with controls (Supplementary Fig. 10a-d). We did not find obvious alterations in Caspase 3 stainings between ShCKO tracheal epithelium and controls at E18.5, suggesting that apoptosis is not 
affected in the mutants (Supplementary Fig. 9d). To examine for changes in the surrounding mesenchyme, we analyzed $\mathrm{SOX}^{+}$chondroblasts, $\alpha-\mathrm{SMA}^{+}$smooth muscle cells and mesenchymal cell proliferation. ShhCKO tracheae exhibited $\mathrm{SOX} 9^{+}$chondroblast condensation defects (Supplementary Fig. 11a), but no obvious SOX9 ${ }^{+}$chondroblast differentiation defects (Supplementary Fig. 11b-d). We also detected reduced numbers of $\alpha$ $\mathrm{SMA}^{+}$smooth muscle cells and increased numbers of $\mathrm{CDH} 1^{-} \mathrm{Ki} 67^{+}$mesenchymal cells compared with controls (Supplementary Fig. 11e, f, g). Since Hh signaling modulates Fgf10 expression in the lung mesenchyme (Volckaert et al., 2013; Balasooriya et al. 2017), we examined Fgflo mRNA expression levels in ShhCKO tracheae. We detected a 1.5 fold increase in FgflO mRNA in ShhCKO mutants (Supplementary Fig. 11h) but this was not sufficient to increase basal cell number, as might have been expected from previous studies. Altogether, these results indicate that loss of Shh function reduces club cell proliferation and interferes with ciliated cell differentiation and secretory cell maturation in the tracheal epithelium. In the tracheal mesenchyme, Shh promotes chondrocyte and smooth muscle morphogenesis.

\section{SMO is required in tracheal epithelial cells for cell proliferation and differentiation}

To investigate whether epithelial inactivation of Hh signaling causes phenotypes similar to those observed in the $S h h C K O$ tracheal epithelium, we selectively deleted the $S h h$ effector Smo in epithelial cells by using $N k x 2.1^{\mathrm{Cre}} ; \mathrm{Smo}^{\text {floxflox }}$ (SmoCKO) mice. The recombination efficiency of the Shhflox and Smoflox alleles has been investigated with a Nestin-driven Cre transgene (Nestin ${ }^{\mathrm{Cre}}$ ) (Machold et al. 2003). In the neural progenitor cells, the phenotypes of $S h h^{\text {null }} / S h h^{\text {flox }}$ and $S m o^{\text {null }} / S m o^{\text {flox }}$ mutant mice were indistinguishable, suggesting that the Shhflox and the Smoflox are recombined with similarly high efficiency (Machold et al. 2003). Additionally, Act $2^{\mathrm{Cre}} ; \mathrm{Smo}^{\text {flox }} / \mathrm{Sm} o^{\text {flox }}$ embryos display similar phenotypes to the $\mathrm{Smo}^{\text {null }} / \mathrm{Smo}{ }^{\text {null }}$ mutants indicating that $S m o^{\text {flox }}$ recombines with high efficiency. ShhCKO embryos display a strong reduction of $S h h$ mRNA in their lungs, suggesting that $S m o C K O$ and $S h h C K O$ represent strong loss of function mutants (Supplementary Fig. 4). We detected decreased numbers of $\mathrm{FOXJ}_{1}{ }^{+}$ciliated cells in $\mathrm{SmoCKO}$ mice (Fig. 3a, b), and an overall reduction of Foxj1 mRNA levels (Fig. 3c) in mutant trachea compared with controls at E18.5. Similarly, we detected fewer acetylated alpha-tubulin ${ }^{+}$mature ciliated cells (Fig. 3d, e) and reduced Tubb4b mRNA levels (Fig. 3c) in SmoCKO animals. SmoCKO tracheae also exhibited decreased numbers of SCGB1A1+ club cells (Fig. 3f, g) and lower Scgblal mRNA levels throughout the tissue (Fig. 3c). Interestingly, SmoCKO tracheae exhibited increased ratios of

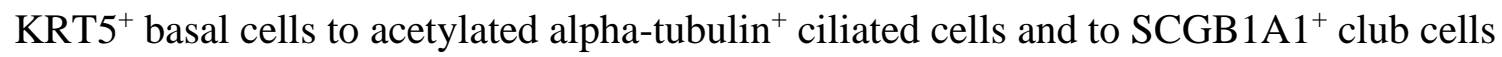
compared with controls (Supplementary Fig. 12a-d). As in the ShhCKO mutants, the SmoCKO tracheae did not exhibit significant defects in the numbers of SCGB3A2 ${ }^{+}$ (Supplementary Fig. 13a, b) or SCGB3A1 ${ }^{+}$(Supplementary Fig. 13c, d) cells, or in the overall expression levels of $S c g b 3 a 2$ or $S c g b 3 a 1$ (Supplementary Fig. 13e) compared with controls. SmoCKO tracheae also displayed reduced $\mathrm{EdU}^{+}$incorporation in $\mathrm{CDH}^{+}$epithelial cells (Fig. $3 \mathrm{~h}, \mathrm{i})$ compared with controls, suggesting that epithelial Smo controls cell proliferation. However, we did not detect any defects in cartilage ring formation or chondroblasts and smooth muscle cells (Supplementary Fig. 14a-e) in SmoCKO tracheae. Notably, the observed phenotypes in SmoCKO mutants are not as severe as those in ShhCKO animals, suggesting 
that the increased severity in the $S h h C K O$ tracheae may be due to the reciprocal signaling from loss of Shh signaling in the surrounding mesenchyme. SHH activation in mesenchymal cells may also indirectly contribute to tracheal epithelial development.

To investigate whether epithelial activation of Hh signaling is sufficient to drive tracheal epithelial cell differentiation, we overexpressed a constitutively active form of Smo, SmoM2

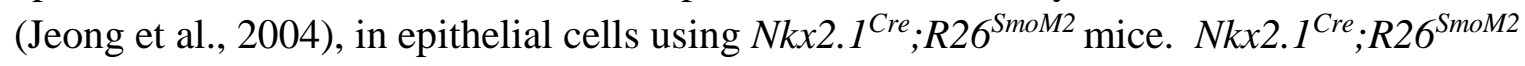
tracheae displayed increased numbers of acetylated alpha-tubulin ${ }^{+}$ciliated cells (Fig. 3j, k) and SCGB1A1 ${ }^{+}$club cells (Fig. 31, m) compared with controls. Overactivation of Smo also resulted in a weak increase in the proportion of $\mathrm{TRP} 63^{+} \mathrm{KRT}^{+}$basal cells in the epithelium but this difference was not statistically significant compared with controls (Supplementary Fig. 15). Collectively, these data indicate that activation of epithelial Hh signaling is required for the proliferation of a subset of tracheal epithelial cells and for the differentiation of secretory and ciliated cell types.

\section{Hh signaling inhibition interferes with the differentiation of human bronchial epithelial cells}

The epithelial structures of the mouse trachea share similarities with human bronchioles, including the cartilaginous rings overlaid by basal progenitor cells and apical secretory and ciliated cells (Rock et al., 2010; Danopoulos et al., 2019). To examine whether Hh signaling is required for human bronchial epithelial (HBE) cell differentiation, we used primary bronchial epithelial cells cultured in vitro at air-liquid interface (ALI) as a model of human airway epithelial development (Schmid et al., 2017). We seeded undifferentiated HBE cells onto transwell filters and removed the medium from the upper chamber to initiate cell differentiation (defined as day 0). We then examined the expression levels of Sonic Hedgehog signaling components in HBE cells and found that SHH, SMO, GLII and GLI2 mRNA were dynamically expressed from day 0 to day 14 (Fig. 4a-d).

Hh signaling inhibition by the SMO inhibitor cyclopamine (Chen et al., 2002) reduces epithelial cell differentiation in the colon (van den Brink et al., 2004), ureter (Bohnenpoll et al., 2017), and nose (Belgacemi et al., 2020). A 9-day cyclopamine treatment led to decreased differentiation of $\mathrm{FOXJ}^{+}$and $\mathrm{RFX}^{+}$ciliated cells and of $\mathrm{MUC} \mathrm{AC}^{+}$secretory cells (Fig. 4e$\mathrm{g}$ and Supplementary Fig. 16a-d), but unaltered TP63 ${ }^{+}$basal cell numbers (Supplementary Fig. 16a, c, e). Similarly, we detected reduced mRNA levels of FOXJ1, TP73, MYB, MUC5AC and HHIP mRNA levels but unchanged TP63 mRNA levels compared with controls (Fig. 4h, Supplementary Fig. 17a-d). Cyclopamine treatment also caused decreased differentiation of acetylated alpha-tubulin ${ }^{+}$ciliated cells and MUC5B ${ }^{+}$secretory cells (Fig. 4i$\mathrm{k}$ ), and an overall reduction of $M U C 5 B$ mRNA levels (Fig. 4h). Next, we examined the expression of $S P D E F$, a transcription factor gene involved in goblet cell differentiation (Park et al., 2007; Chen et al., 2009), and observed significantly reduced SPDEF mRNA levels after cyclopamine treatment compared with controls (Fig. 4h). To test whether the epithelial differentiation defects due to Hh signaling inhibition correlate with alterations in the Notch pathway we examined the levels of Notch signaling components. We did not detect significant changes in JAG1, JAG2, NOTCH2, HES1 or HEY1 mRNA levels upon cyclopamine treatment (Supplementary Fig. 17e-i). Moreover, we did not observe significant 
changes in the number of NGFR ${ }^{+}$basal cells (Supplementary Fig. 18a, b). A 9-day treatment with $10 \mu \mathrm{M}$ GANT 58, a GLI1 inhibitor (Lauth et al., 2007; Beauchamp et al., 2009), also decreased the relative numbers of FOXJ1+ ciliated cells (Supplementary Fig. 19a, b) and MUC5 $\mathrm{AC}^{+}$secretory cells (Supplementary Fig. 19a, c), as well as HHIP mRNA levels (Supplementary Fig. 19d), suggesting that Hh signaling regulates HBE cell differentiation in a GLI1-dependent manner. Next, we asked whether SHH could induce HBE cell differentiation. A 9 day-long treatment with recombinant human $\mathrm{SHH}(\mathrm{H}-\mathrm{SHH})$ increased the relative number of $\mathrm{FOXJ1}^{+}$ciliated cells (Fig. 41, m) and MUC5AC ${ }^{+}$secretory cells (Fig. 4l, n), accompanied by up-regulated FOXJ1, MUC5AC and HHIP mRNA levels (Fig. 4o and Supplementary Fig. 19e), at day 14 compared with controls. These data indicate that canonical Sonic Hedgehog signaling drives HBE cell differentiation.

\section{Hh signaling inhibition compromises HBE cell proliferation}

To investigate Hh signaling in HBE cell proliferation, we analyzed the number of HBE cells in S-phase in ALI cultures with or without cyclopamine treatment. We conducted a dual pulse labeling using EdU and BrdU incorporation during HBE cell proliferation from day 0 to day 7 to follow proliferation at different stages of culture and differentiation (Fig. 5a). High Alexa Fluor 555-derived fluorescence intensity was observed in most HBE cells after a 12hour EdU treatment at day 0 (Supplementary Fig. 20a, b), indicating that undifferentiated HBE cells undergo active proliferation. To examine proliferation characteristics of these $\mathrm{EdU}^{+}$cells, we traced cell proliferation at later stages by adding BrdU into the culture medium from day 2.5 to day 6.5 and performing staining and analysis 12 hours after each pulse labeling (Fig. 5a). At day 3, both high and low Alexa Fluor 555-derived fluorescence intensities were observed in HBE cells (Fig. 5b), indicating different proliferative activities among HBE cells from day 0 to day 3. High Alexa Fluor 488-derived fluorescence intensity reflecting high BrdU incorporation was observed only in some of the cells with low Alexa Fluor 555-derived fluorescence intensity at day 3 (Fig. 5b), indicating further proliferation of some dividing cells from day 0. Ki67 was detected mainly in $\mathrm{BrdU}^{+}$cells (Fig. 5b) and a subset of cells with low Alexa Fluor 555-derived fluorescence intensity (Fig. 5b). At day 5, cells with lower Alexa Fluor 555-derived fluorescence intensity were observed compared with day 3 (Fig. 5b, c), and $\mathrm{BrdU}^{+}$or $\mathrm{Ki}^{+} 7^{+}$signals were detected in only a subset of these cells (Fig. 5c), indicating that few of the EdU ${ }^{+}$cells divided from day 3 to day 5. At day 7, even fewer $\mathrm{BrdU}^{+}$or $\mathrm{Ki} 7^{+}$cells exhibited low or undetectable Alexa Fluor 555-derived fluorescence intensity compared with day 5 (Fig $5 \mathrm{~d}$ ), suggesting that only a few of the EdU ${ }^{+}$ labelled cells at day 0 continue to divide from day 5 to day 7 , or that the label became diluted after serial rounds of proliferation. Cyclopamine treatment led to a general decrease in BrdU incorporation in cells with Alexa Fluor 555-derived fluorescence intensity as well as reduced Ki67 immunostaining at day 3 (Fig. 5e-f), day 5 (Fig. 5g-h) and day 7 (Fig. 5i-j), indicating that $\mathrm{Hh}$ signaling is required continuously for DNA synthesis in proliferating HBE cells. To test whether Hh signaling is required for cell proliferation during differentiation of HBE cells, we treated HBE cells in ALI with $10 \mu \mathrm{M}$ cyclopamine from day 5 to day 14, when ciliated cells and secretory cells begin to differentiate. Again, after a 9-day, cyclopamine treatment, we observed an overall decrease in proliferation of epithelial cells (Supplementary Fig. 21a, 
b). Altogether, these results suggest that Hh signaling is required for HBE cell proliferation at both the cell expansion and differentiation stages.

\section{DISCUSSION}

Genetic studies in mice have linked Hh signaling to several human congenital malformations of the trachea and bronchi including tracheoesophageal fistula and possible tracheomalacia (Sala et al., 2011; Miller et al., 2004; Motoyama et al., 1998; Park et al., 2009). Recently, whole-exome sequencing of pediatric patients and their parents revealed a de novo mutation in $S H H$ (p.Asp279Tyr) in children with complete tracheal ring deformity (CTRD) (Sinner et al., 2019), a condition characterized by circumferentially continuous or nearly-continuous cartilaginous tracheal rings (Sahoo et al., 2009; Faust et al., 1998), variable degrees of tracheal stenosis and/or shortening, and/or pulmonary arterial sling anomaly (Berdon et al., 1984; Lee et al., 1996). Given the importance of SHH in tracheal development and congenital disorders, it is important to understand the specific contributions of paracrine and autocrine signaling activation. Our analysis of the epithelial ShhCKO phenotypes suggests that epithelial derived SHH mediate tracheal cartilage formation possibly by activating $\mathrm{Hh}$ signaling in mesenchyme. Sox 9 and Col2al mRNA levels are both reduced in the tracheal mesenchyme of Shh null mice (Park et al., 2010), and presumably other targets involved in tracheal cartilage formation are also affected. Previous work has also shown that Shh and Fgf10 exhibit genetic interaction during tracheal cartilage ring formation, and suggested that mesenchymal FgflO control epithelial growth, cartilage patterning and epithelial Shh expression (Sala et al., 2011). Nevertheless, our epithelial cell specific deletion of Shh leads to more severe tracheal cartilage defects compared with the FgflO or Fgfr $2 b$ null allele (Sala et al., 2011), suggesting that $S h$ acts via additional target (s) in the mesenchyme to regulate tracheal patterning. In bladder, epithelial cell derived SHH increases stromal expression of Wnt2 and Wnt4, which in turn stimulates the proliferation of both epithelial and stromal cells on injury (Shin et al., 2011). Interestingly, both global knockout of Wnt4 and epithelial cell specific deletion of Wntless, a cargo receptor facilitating Wnt ligand secretion (Bänziger et al., 2006), causes defects in tracheal cartilage ring formation (Snowball et al., 2015; Caprioli et al., 2015). Wnt signaling is also essential for human airway epithelial cell differentiation and proliferation (Schmid et al., 2017). However, it is unknown whether Wnt signaling is required for tracheal epithelial cell differentiation or proliferation in vivo. It would be interesting to examine epithelial cell differentiation in Wnt signaling inactivation mutants, and test for the possible crosstalk between $\mathrm{Hh}$ and Wnt signaling during tracheal formation.

The $S m o C K O$ analysis also uncovers a new epithelial function for $S h h$, where Smo controls cell-autonomously the proliferation of epithelial cells and their differentiation into SCGB1A1 ${ }^{+}$club cells and ciliated cells. The decreased number of ciliated and SCGB1A1 ${ }^{+}$ cells in the $S m o C K O$ trachea could be due to the proliferation defect of a common progenitor or due to a continuous requirement of epithelial Smo for cell differentiation of the progenitors towards the ciliated and SCGB1A1+ lineages. This autocrine function of Hh signaling is also retained in human bronchial cells, where both SMO and GLI inhibition reduce epithelial proliferation and differentiation towards the secretory and ciliated lineages. The overexpression analysis of the activated SmoM2 allele in the mouse and the effects of SHH 
addition to the human bronchial epithelial cell further argue for a direct role of Hh signaling in epithelial cell differentiation. Our work suggests a functional separation of the tracheal defects observed in mouse mutants and patients with mutations in Hh pathway genes.

Cartilage abnormalities and other mesenchymal defects are due to the paracrine function of Shh, whereas tracheal lumen stenosis and respiratory dysfunctions maybe due to the combined functions of $\mathrm{HH}$ and its downstream effectors in both the epithelium and mesenchyme. 


\section{MATERIAL AND METHODS}

Mice

All mouse experiments were performed under standard conditions in accordance with German federal ethical and animal welfare guidelines (Ethical Permit number GI 20/10, Nr. G 29/2019) and Swedish ethical regulations approved by the Northern Stockholm Animal Ethics Committee (Ethical Permit numbers N254/2014 and 15196/2018). All breeding colonies were maintained under cycles of 12-hour light and 12-hour dark. $N k x 2.1^{\text {Cre }}$ (2), Shh flox (2), $S m o^{f l o x}(60), R 26 S_{m o} o^{2}(41)$ alleles have been previously described.

\section{SCRINSHOT detection of mRNA}

E13.5 and E15.5 WT tracheae were fixed in 4\% PFA for 30-45 min at $4{ }^{\circ} \mathrm{C}$. Longitudinal cryosections of the trachea $(10 \mu \mathrm{m})$ were prepared and the SCRINSHOT protocol (25) was used for probe design and in situ detection of mRNA transcripts. Sequences of probes are listed in the supplementary table.

\section{Alcian blue staining of cartilage}

Tracheal cryosections $(10 \mu \mathrm{m})$ were fixed in $4 \%$ paraformaldehyde for $20 \mathrm{~min}$, treated with $3 \%$ acetic acid solution for $3 \mathrm{~min}$, stained in $0.05 \%$ alcian blue for $10 \mathrm{~min}$ and counterstained with $0.1 \%$ nuclear fast red solution for $5 \mathrm{~min}$. For whole-mount staining of tracheal cartilage, dissected tracheae were fixed in $95 \%$ ethanol for $12 \mathrm{~h}$ followed by overnight staining with $0.03 \%$ alcian blue dissolved in $80 \%$ ethanol and $20 \%$ acetic acid. Samples were cleared in $2 \%$ $\mathrm{KOH}$.

\section{Immunostaining of cryosections}

Tracheae were dissected in PBS, fixed in $4 \%$ paraformaldehyde overnight at $4{ }^{\circ} \mathrm{C}$, incubated in $10 \%$ sucrose and $30 \%$ sucrose for $24 \mathrm{~h}$ each at $4{ }^{\circ} \mathrm{C}$, mounted in OCT embedding compound, and sectioned at $10 \mu \mathrm{m}$. To perform immunostaining, sections were fixed in $4 \%$ paraformaldehyde $10 \mathrm{~min}$ at $4{ }^{\circ} \mathrm{C}$, followed by incubation in permeabilization solution $(0.3 \%$ Triton X-100/PBS) for $15 \mathrm{~min}$ at RT, incubated in blocking solution ( $5 \% \mathrm{FBS} / \mathrm{PBS} / 3 \% \mathrm{BSA})$ for $1 \mathrm{~h}$ at RT, incubated in primary antibodies overnight at $4{ }^{\circ} \mathrm{C}$, washed, incubated in secondary antibodies for $2 \mathrm{~h}$ at RT, washed, and then mounted for imaging.

\section{Explant culture of mouse embryonic tracheae and lungs, and EdU incorporation and detection}

Tracheae and lungs were isolated from E18.5 embryos and cultured using an established protocol (61). For EdU incorporation, isolated tracheae and lungs were cultured in DMEM/F12 medium containing $10 \mu \mathrm{M}$ EdU at $37{ }^{\circ} \mathrm{C}$ in a $5 \% \mathrm{CO}_{2}$ incubator for $20 \mathrm{~h} .0 .1 \% \mathrm{DMSO}$ was used as a control. Tracheae were fixed in $4 \%$ paraformaldehyde overnight at $4{ }^{\circ} \mathrm{C}$, incubated in $10 \%$ sucrose and $30 \%$ sucrose for $24 \mathrm{~h}$ each at $4{ }^{\circ} \mathrm{C}$, mounted in OCT embedding compound, and sectioned at $10 \mu \mathrm{m}$. To perform EdU detection and CDH1 immunostaining, sections were fixed in $4 \%$ paraformaldehyde $10 \mathrm{~min}$ at $4{ }^{\circ} \mathrm{C}$ followed by incubation in permeabilization solution ( $0.3 \%$ Triton $\mathrm{X}-100 / \mathrm{PBS})$ for $15 \mathrm{~min}$ and in blocking solution (5\% 
FBS/PBS/3\% BSA) for $1 \mathrm{~h}$ at RT. Samples were incubated in EdU reaction cocktail prepared according to the manufacturer's instruction (Click-iT® EdU Imaging Kit, Thermo Fisher Scientific, C10338) for $30 \mathrm{~min}$, washed, incubated in the CDH1 primary antibody for $4 \mathrm{~h}$ at $\mathrm{RT}$, washed, incubated in the secondary antibody for $2 \mathrm{~h}$ at RT, washed, and then mounted for imaging.

\section{HBE cell ALI culture, and chemical treatment}

Primary human bronchial epithelial (HBE) cells (material obtained from the UGMLC/DZLBiobank, Dr. C. Ruppert/ Prof. A. Günther and approved by the local ethic committee, AZ 85/15) were isolated and cultivated under air-liquid interface conditions to form welldifferentiated, pseudostratified cultures as described previously (62). Isolated HBE cells were maintained and expanded (one passage) in T75 flasks in hormone- and growth factorsupplemented airway epithelial cell growth medium (AEGM, ready-to-use; PromoCell) at $37^{\circ} \mathrm{C}$ in a $5 \% \mathrm{CO}_{2}$ incubator. At $80 \%$ confluence, cells were detached with $0.05 \%$ trypsinEDTA (Gibco) and seeded on membrane supports (12 mm Transwell culture inserts, $0.4 \mu \mathrm{m}$ pore size, Costar) coated with $0.05 \mathrm{mg}$ collagen from calf skin (Sigma-Aldrich) in ready-touse AEGM supplemented with $1 \%$ penicillin/streptomycin. HBE cells were cultured for two days until they reached complete confluence. The apical medium was then removed and the basal medium was replaced by a 1:1 mixture of DMEM (Sigma) and ready-to-use AEGM supplemented with $60 \mathrm{ng} / \mathrm{ml}$ retinoic acid (Sigma). Cultures were maintained under air-liquid interface conditions by changing the medium in the basal filter chamber three times a week. For cyclopamine (1623, TOCRIS) treatment, a $5 \mathrm{mM}$ stock solution was diluted to $10 \mu \mathrm{M}$. For GANT 58 (3889, TOCRIS) treatment, a $10 \mathrm{mM}$ stock solution was diluted to $10 \mu \mathrm{M}$. For recombinant human SHH (H-SHH) (R\&D Systems, 1845-SH-025) treatment, a $200 \mu \mathrm{g} / \mu 1$ stock solution was diluted to $100 \mathrm{ng} / \mathrm{ml}$. Epithelial cells were cultured in differentiation medium containing the above chemicals or $\mathrm{H}-\mathrm{SHH}$ at $37{ }^{\circ} \mathrm{C}$ in a $5 \% \mathrm{CO}_{2}$ incubator from day 5 to day 14 . The medium was replaced every $24 \mathrm{~h}$ before collection for analysis.

\section{EdU and BrdU incorporation and detection in $\mathrm{HBE}$ cells}

For EdU incorporation in HBE cells, a $10 \mathrm{mM}$ EdU stock solution was diluted to $10 \mu \mathrm{M}$. For BrdU incorporation, a $10 \mathrm{mM}$ BrdU stock solution was diluted to $10 \mu \mathrm{M}$. HBE cells were cultured in differentiation medium with EdU or BrdU at $37^{\circ} \mathrm{C}$ in a $5 \% \mathrm{CO}_{2}$ incubator for $12 \mathrm{~h}$ at indicated time point. For EdU and BrdU detection, ALI cultures were fixed in $4 \%$ paraformaldehyde $20 \mathrm{~min}$ at RT, followed by incubation in permeabilization solution $(0.3 \%$ Triton X-100/PBS) for $15 \mathrm{~min}$ and in blocking solution (5\% FBS/PBS/3\% BSA) for $1 \mathrm{~h}$ at RT. Samples were incubated in EdU reaction cocktail prepared accouding to the manufacturer's instruction (Click-iT® EdU Imaging Kit, Thermo Fisher Scientific, C10338) for $30 \mathrm{~min}$, washed, incubated in the BrdU antibody for $4 \mathrm{~h}$ at RT, washed, incubated in the secondary antibody for $2 \mathrm{~h}$ at RT, washed, and then mounted for imaging.

\section{Reverse transcription quantitative PCR (RT-qPCR)}

Total RNA extraction was conducted using a miRNeasy Mini Kit (Qiagen, 217004). cDNA was synthesized using the Maxima First Strand cDNA Synthesis Kit (Thermo Fisher Scientific, K1641), according to manufacturer's instructions. Quantitative real-time PCR was 
performed using LightCycler $^{\circledR} 480$ II (Roche) and iTaq $^{\text {TM }}$ Universal SYBR ${ }^{\circledR}$ Green Supermix (Bio-Rad, 1725122). The following primers were used: $m A c t b$ forward 5'CGGCCAGGTCATCACTATTGGCAAC-3' and $m A c t b$ reverse 5'GCCACAGGATTCCATACCCAAGAAG-3'; $m S h h$ forward 5'GGCTGATGACTCAGAGGTGCAAAG-3' and $m S h h$ reverse 5'GCTCGACCCTCATAGTGTAGAGAC-3'; mGlil forward 5'GCCTGGAGAACCTTAGGCTGGA-3' and $m$ Glil reverse 5'-ACAGGTGCGCCAGCGTG3'; mGli2 forward 5'-GCCCTGGAGAGTCACCCTT-3' and $m$ Gli2 reverse 5'TGCACAGACCGGAGGTAGT-3'; mSmo forward 5'-GAGCGTAGCTTCCGGGACTA-3' and $m S m o$ reverse 5'-CTGGGCCGATTCTTGATCTCA-3'; mFoxj1 forward 5'GAGTGAGGGCAAGAGACTGG-3' and mFoxj1 reverse 5'TCAAGTCAGGCTGGAAGGTT-3'; $m$ Tubb4b forward 5'AACCCGGCACCATGGACTCTGT-3' and $m T u b b 4 b$ reverse $5^{\prime}-$ TGCCTGCTCCGGATTGACCAAATA-3'; mScgblal forward 5'ATGAAGATCGCCATCACAATCAC-3' and $m S c g b l a l$ reverse 5'GGATGCCACATAACCAGACTCT-3'; mScgb3al forward 5'ACCACCACCTTTCTAGTGCTC-3' and $m S c g b 3 a l$ reverse $5^{\prime}-$ GGCTTAATGGTAGGCTAGGCA-3'; $m S c g b 3 a 2$ forward 5'GCTGGTATCTATCTTTCTGCTGGTG-3' and $m S c g b 3 a 2$ reverse 5'ACAACAGGGAGACGGTTGATGAGA-3'; mFoxpl forward 5'CGAATGTTTGCTTACTTCCGACGC-3' and $m F$ oxpl reverse $5^{\prime}$ ACTTCATCCACTGTCCATACTGCC-3'; hRPLRO forward 5'CCAGCAGGTGTTCGACAAT-3' and $h R P L R O$ reverse $5^{\prime}-$

CAGGAAGCGAGAATGCAGA-3'; $h S H H$ forward 5'-AAGGACAAGTTGAACGCTTTGG$3^{\prime}$ and $h S H H$ reverse 5'-TCGGTCACCCGCAGTTTC-3'; $h G L I 1$ forward 5'-

TCTCAAAGTGGGAGGCACAA- $3^{\prime}$ and $h G L I 1$ reverse $5^{\prime}$ CCCTTAGGAAATGCGATCTG-3'; $h$ GLI2 forward 5'-TTATGGGCATCCTCTCTGGT-3' and $h G L I 2$ reverse 5'-CGGAGCAGAGTATCCAGTAT-3'; $h S M O$ forward 5'GAAGTGCCCTTGGTTCGGA-3' and $h S M O$ reverse 5'-GCAGGGTAGCGATTCGAGTT3'; hFOXJ1 forward 5'-GCCTCCCTACTCGTATGCCA-3' and $h F O X J 1$ reverse 5'GCCGACAGGGTGATCTTGG-3'; hMUC5AC forward 5'GCTCAGCTGTTCTCTGGATGAG-3' and $h M U C 5 A C$ reverse $5^{\prime}-$ TTACTGGAAAGGCCCAAGCA-3'; $h M U C 5 B$ forward 5'ACATGTGTACCTGCCTCTCTGG-3' and $h M U C 5 B$ reverse $5^{\prime}-$ TCTGCTGAGTACTTGGACGCTC-3'; hNOTCH2 forward 5'TGGTGGCAGAACTGATCAAC-3' and $h N O T C H 2$ reverse $5^{\prime}-$ CTGCCCAGTGAAGAGCAGAT-3'; $h J A G l$ forward 5'-GAATGGCAACAAAACTTGCAT$3^{\prime}$ and $h J A G 1$ reverse 5'- AGCCTTGTCGGCAAATAGC -3'; hJAG2 forward 5'-

GAGCTCTGCGACACCAATC-3' and $h J A G 2$ reverse $5^{\prime}$ - TCATTGACCAGGTCGTAGCA 3'; hHES1 forward 5'- TTACGGCGGACTCCATGT-3' and hHES1 reverse 5'AGAGGTGGGTTGGGGAGT-3'; $h H E Y 1$ forward 5'GATGATCAGCTTTATCCAAGAAAGA-3' and $h H E Y 1$ reverse $5^{\prime}-$ CAGTTTGTACATTCACCTTTCTGC-3'; $h M Y B$ forward 5'CCGGGAAGAGGATGAAAAAC $-3^{\prime}$ and $h M Y B$ reverse $5^{\prime}-$ 
TTTCCAGTCATCTGTTCCATTC-3'; $h T P 73$ forward 5'-CCACTGGTGGACTCCTATCG$3^{\prime}$ and $h T P 73$ reverse 5'- CTGTAGGTGACTCGGCCTCT-3'; $h T P 63$ forward 5'GAAGATCAAAGAGTCCCTGGAA-3' and $h T P 63$ reverse 5'GCTGTTGCCTGTACGTTTCA-3'

\section{Antibodies}

The following antibodies were used: Rat anti-CDH1 (1:200, Santa Cruz, sc-59778); Mouse anti-CDH1 (1:100, BD Biosciences, 560062); Rabbit anti Cleaved Caspase-3 (1:600, Cell Signaling Technologies, \#9661); Goat anti-SCGB1A1 (1:200, Santa Cruz, T-18); Rabbit antiNKX2.1 (1:400, Santa Cruz, H-190); Mouse anti-acetyl-alpha tubulin (1:2000, Sigma, MABT868); Mouse anti-FOXJ1 (1:400, Thermo Fisher Scientific, 14-9965-82); Rabbit antiMUC5AC (1:400, Santa Cruz, H-160); Rabbit anti-MUC5B (1:400, Novus Biologicals, NBP1-92151); Mouse anti-BrdU (1:400, Thermo Fisher Scientific, B35141); Hamster antiPDPN (1:20, DSHB, 8.1.1); Rat anti-SCGB3A1 (1:200, R\&D Systems, MAB2954); Rat antiSCGB3A2 (1:200, R\&D Systems, MAB3465); Rabbit anti-Ki67 (1:400, Thermo Fisher Scientific, PA5-19462); Goat anti-NGFR (1:200, Santa Cruz, C-20); Mouse anti- $\alpha$-SMA-Cy3 (1:1000, Sigma-Aldrich, C6198); Rabbit anti-SOX9 (1:400, Millipore, AB5535MA); Goat anti-SOX9 (1:500, R\&D Systems, AF3075); Rat anti-Cd140a (1:100, Biolegend, 135901); Rabbit anti-RFX3 (1:500, Sigma, HPA035689); Mouse anti-TRP63 (1:500, Abcam, ab735); Rabbit anti-TRP63 (1:100, Cell Signaling Technology, \#13109S). Chicken anti-KRT5 (1:400, Biosite, 905901).

\section{Imaging}

Imaging of wholemount tracheae, trachea sections and ALI cultures was performed using a Nikon SMZ25, Zeiss 880 upright laser scanning confocal microscope, Zeiss 780 laser scanning confocal microscope or Zeiss Axio Observer Z.2 fluorescent microscope (Carl Zeiss Microscopy $\mathrm{GmbH}$ ). SCRINSHOT imaging was performed using a Zeiss Axio Observer Z.2 fluorescent microscope (Carl Zeiss Microscopy $\mathrm{GmbH}$ ) with a Colibri led light source, equipped with a Zeiss AxioCam 506 Mono digital camera and an automated stage. Quantification of cell number was performed using ImageJ (http://rsbweb.nih.gov/ij/).

\section{Statistical analysis}

Statistical analyses were performed using GraphPad software. P values were calculated by Student's t-test $\mathrm{P}$ values were calculated by Student's t-test. $\mathrm{P}<0.05$ was considered significant. 


\section{Reference}

Balasooriya, G.I., Goschorska, M., Piddini, E., and Rawlins, E.L. (2017). FGFR2 us reguired for airway basal cell self-renewal and terminal differentiation. Development. 144, $1600-1606$

Bals, R., C. Beisswenger, S. Blouquit, and T. Chinet. (2004). Isolation and air-liquid interface culture of human large airway and bronchiolar epithelial cells. J Cyst Fibros. 2, 49-51.

Bänziger, C., D. Soldini, C. Schütt, P. Zipperlen, G. Hausmann, and K. Basler. (2006). Wntless, a conserved membrane protein dedicated to the secretion of Wnt proteins from signaling cells. Cell. 125, 509-22.

Beauchamp, E., G. Bulut, O. Abaan, K. Chen, A. Merchant, W. Matsui, Y. Endo, J.S. Rubin, J. Toretsky, and A. Uren. (2009). GLI1 is a direct transcriptional target of EWSFLI1 oncoprotein. J Biol Chem. 284, 9074-82.

Belgacemi, R., E. Luczka, J. Ancel, Z. Diabasana, J.M. Perotin, A. Germain, N. Lalun, P. Birembaut, X. Dubernard, J.C. Mérol, et al. (2020). Airway epithelial cell differentiation relies on deficient Hedgehog signalling in COPD. EBioMedicine. 51, 102572.

Bellusci, S., Y. Furuta, M.G. Rush, R. Henderson, G. Winnier, and B.L. Hogan. (1997). Involvement of Sonic hedgehog (Shh) in mouse embryonic lung growth and morphogenesis. Development. 124, 53-63.

Berdon, W.E., D.H. Baker, J.T. Wung, A. Chrispin, K. Kozlowski, M. de Silva, P. Bales, and B. Alford. (1984). Complete cartilage-ring tracheal stenosis associated with anomalous left pulmonary artery: the ring-sling complex. Radiology. 152, 57-64.

Berman, D.M., S.S. Karhadkar, A. Maitra, R. Montes De Oca, M.R. Gerstenblith, K. Briggs, A.R. Parker, Y. Shimada, J.R. Eshleman, D.N. Watkins, et al. (2003). Wide spread requirement for Hedgehog ligand stimulation in growth of digestive tract tumours. Nature. 425, 846-51.

Bohnenpoll, T, A.B. Wittern, T.M. Mamo, A.C. Weiss, C. Rudat, M.J. Kleppa, K. Schuster-Gossler, I. Wojahn, T.H. Lüdtke, M.O. Trowe, et al. (2017). A SHHFOXF1-BMP4 signaling axis regulating growth and differentiation of epithelial and mesenchymal tissues in ureter development. PLoS Genet. 13, e1006951.

Brand-Saberi, B.E.M., and T. Schäfer. (2014). Trachea: anatomy and physiology. Thorac Surg Clin. 24, 1-5.

Caprioli, A., A. Villasenor, L.A. Wylie, C. Braitsch, L. Marty-Santos, D. Barry, C.M. Karner, S. Fu, S.M. Meadows, T.J. Carroll, et al. (2015). Wnt4 is essential to normal mammalian lung development. Dev Biol. 406, 222-34.

Chen, G., T.R. Korfhagen, Y. Xu, J. Kitzmiller, S.E. Wert, Y. Maeda, A. Gregorieff, H. Clevers, and J.A. Whitsett. (2009). SPDEF is required for mouse pulmonary goblet cell differentiation and regulates a network of genes associated with mucus production. J Clin Invest. 119, 2914-24. 
Chen, J.K., J. Taipale, M.K. Cooper, and P.A. Beachy. (2002). Inhibition of Hedgehog signaling by direct binding of cyclopamine to Smoothened. Genes Dev. 16, 2743-8.

Danopoulos, S., J. Shiosaki, and D. Al Alam. (2019). FGF Signaling in Lung Development and Disease: Human Versus Mouse. Front Genet. 10, 170.

Del Moral, P.M., and D. Warburton. (2010). Explant culture of mouse embryonic whole lung, isolated epithelium, or mesenchyme under chemically defined conditions as a system to evaluate the molecular mechanism of branching morphogenesis and cellular differentiation. Methods Mol Biol. 633, 71-9.

Ericson, J., J. Muhr, M. Placzek, T. Lints, T.M. Jessell, and T. Edlund. (1995). Sonic hedgehog induces the differentiation of ventral forebrain neurons: a common signal for ventral patterning within the neural tube. Cell. 81, 747-56.

Faust, R.A., B. Stroh, and F. Rimell. (1998). The near complete tracheal ring deformity. Int J Pediatr Otorhinolaryngol. 45, 171-6.

Freestone, S.H., P. Marker, O.C. Grace, D.C. Tomlinson, G.R. Cunha, P. Harnden, and A.A. Thomson. (2003). Sonic hedgehog regulates prostatic growth and epithelial differentiation. Dev Biol. 264, 352-62.

Gagné-Sansfaçon, J.M. Allaire, C. Jones, F. Boudreau, and N. Perreault. (2014). Loss of Sonic hedgehog leads to alterations in intestinal secretory cell maturation and autophagy. PLoS One. 9, e98751.

Gerhardt, B., L. Leesman, K. Burra, J. Snowball, R. Rosenzweig, N. Guzman, M. Ambalavanan, and D. Sinner. (2018). Notum attenuates $\mathrm{Wnt} / \beta$-catenin signaling to promote tracheal cartilage patterning. Dev Biol. 436, 14-27.

Guha, A., M. Vasconcelos, Y. Cai, M. Yoneda, A. Hinds, J. Qian, G. Li, L. Dickel, J.E. Johnson, S. Kimura, et al. (2012). Neuroepithelial body microenvironment is a niche for a distinct subset of Clara-like precursors in the developing airways. Proc Natl Acad Sci U $S$ A. 109, 12592-7.

Herriges, J.C., J.M. Verheyden, Z. Zhang, P. Sui, Y. Zhang, M.J. Anderson, D.A. Swing, Y. Zhang, M. Lewandoski, and X. Sun. (2015). FGF-Regulated ETV Transcription Factors Control FGF-SHH Feedback Loop in Lung Branching. Dev Cell. 35, 322-32.

Hines, E.A., M.K. Jones, J.M. Verheyden, J.F. Harvey, and X. Sun. (2013). Establishment of smooth muscle and cartilage juxtaposition in the developing mouse upper airways. Proc Natl Acad Sci U S A. 110, 19444-9.

Jeong, J., J. Mao, T. Tenzen, A.H. Kottmann, and A.P. McMahon. (2004). Hedgehog signaling in the neural crest cells regulates the patterning and growth of facial primordia. Genes Dev. 18, 937-51.

Kiyokawa, H., A. Yamaoka, C. Matsuoka, T. Tokuhara, T. Abe, and M. Morimoto. (2021). Airway basal stem cells reutilize the embryonic proliferation regulator, Tgf $\beta$-Id2 axis, for tissue regeneration. Dev Cell. 56, 1917-1929.

Kugler, M.C., A.L. Joyner, C.A. Loomis, and J.S. Munger. (2015). Sonic hedgehog signaling in the lung. From development to disease. Am J Respir Cell Mol Biol. 52, 1-13. 
Lauth M., A. Bergström, T. Shimokawa, and R. Toftgård. (2007). Inhibition of GLImediated transcription and tumor cell growth by small-molecule antagonists. Proc Natl Acad Sci U S A. 104, 8455-60.

Lee, J.C., G.S. Kim, S.J. Lee, C.G. Yoo, Y.W. Kim, and S.K. Han. (1996). An adult case of pulmonary sling with complete tracheal ring. Korean J Intern Med. 11, 175-7.

Li, S., Y. Wang, Y, Zhang, M.M. Lu, F.J. DeMayo, J.D. Dekker, P.W. Tucker, and E.E. Morrisey. (2012). Foxp1/4 control epithelial cell fate during lung development and regeneration through regulation of anterior gradient 2. Development. 139, 2500-9.

Li, Y., H. Zhang, S.C. Choi, Y. Litingtung, and C. Chiang. (2004). Sonic hedgehog signaling regulates Gli3 processing, mesenchymal proliferation, and differentiation during mouse lung organogenesis. Dev Biol. 270, 214-31.

Long, F., X..M Zhang, S. Karp, Y. Yang, and A.P. McMahon. (2001). Genetic manipulation of hedgehog signaling in the endochondral skeleton reveals a direct role in the regulation of chondrocyte proliferation. Development. 128, 5099-108.

Machold, R., Hayashi, S., Rutlin, M., Muzumbar, M.D., Nery, S., Corbin, J.G., GritliLinde, A., Dellovade, T., Porter, J.A., Rubin, L.L., et al. (2003). Sonic Hedgehog Is Required for Progenitor Cell Maintenance in Telencephalic Stem Cell Niches. Neuron. 39, 937-950.

Merchant, A., G. Joseph, Q. Wang, S. Brennan, and W. Matsui. (2010). Gli1 regulates the proliferation and differentiation of HSCs and myeloid progenitors. Blood. 115, 2391-6.

Miller, L.A., S.E. Wert, J.C. Clark, Y. Xu, A.K. Perl, and J.A. Whitsett. (2004). Role of Sonic hedgehog in patterning of tracheal-bronchial cartilage and the peripheral lung. Dev Dyn. 231, 57-71.

Montoro, D.T., A.L. Haber, M. Biton, V. Vinarsky, B. Lin, S.E. Birket, F. Yuan, S. Chen, H.M. Leung, J. Villoria, et al. (2018). A revised airway epithelial hierarchy includes CFTR-expressing ionocytes. Nature. 560, 319-324.

Motoyama, J., J. Liu, R. Mo, Q. Ding, M. Post, and C.C. Hui. (1998). Essential function of Gli2 and Gli3 in the formation of lung, trachea and oesophagus. Nat Genet. 20, 54-7.

Nikolić, M.Z., O. Caritg, Q. Jeng, J.A. Johnson, D. Sun, K.J. Howell, J.L. Brady, U. Laresgoiti, G. Allen, R. Butler, et al. (2017). Human embryonic lung epithelial tips are multipotent progenitors that can be expanded in vitro as long-term self-renewing organoids. Elife. 6, e26575.

Park, K.S., T.R. Korfhagen, M.D. Bruno, J.A. Kitzmiller, H. Wan, S.E. Wert, G.K. Khurana Hershey, G. Chen, and J.A. Whitsett. (2007). SPDEF regulates goblet cell hyperplasia in the airway epithelium. J Clin Invest. 117, 978-88.

Park, J., J.J. Zhang, A. Moro, M. Kushida, M. Wegner, and P.C. Kim. (2010). Regulation of Sox9 by Sonic Hedgehog (Shh) is essential for patterning and formation of tracheal cartilage. Dev Dyn. 239, 514-26. 
Peng, T., D.B. Frank, R.S. Kadzik, M.P. Morley, K.S. Rathi, T. Wang, S. Zhou, L. Cheng, M.M. Lu, and E.E. Morrisey. (2015). Hedgehog actively maintains adult lung quiescence and regulates repair and regeneration. Nature. 526, 578-82.

Pepicelli, C.V., P.M. Lewis, and A.P. McMahon. (1998). Sonic hedgehog regulates branching morphogenesis in the mammalian lung. Curr Biol. 8, 1083-6.

Plaisant, M., S. Giorgetti-Peraldi, M. Gabrielson, A. Loubat, C. Dani, P. Peraldi. 2011. Inhibition of hedgehog signaling decreases proliferation and clonogenicity of human mesenchymal stem cells. PLoS One. 6, e16798.

Plasschaert, L.W., R. Žilionis, R. Choo-Wing, V. Savova, J. Knehr, G. Roma, A.M. Klein, and A.B. Jaffe. (2018). A single-cell atlas of the airway epithelium reveals the CFTR-rich pulmonary ionocyte. Nature. 560, 377-381.

Raleigh, D.R., P.K. Choksi, A.L. Krup, W. Mayer, N. Santos, and J.F. Reiter. (2018). Hedgehog signaling drives medulloblastoma growth via CDK6. J Clin Invest. 128, 120124.

Reynolds, S.D., P.R. Reynolds, G.S. Pryhuber, J.D. Finder, and B.R. Stripp. (2002). Secretoglobins SCGB3A1 and SCGB3A2 define secretory cell subsets in mouse and human airways. Am J Respir Crit Care Med. 166, 1498-509.

Riddle, R.D., R.L. Johnson, E. Laufer, and C. Tabin. (1993). Sonic hedgehog mediates the polarizing activity of the ZPA. Cell. 75, 1401-16.

Rock, J.R., S.H. Randell, and B.L. Hogan. (2010). Airway basal stem cells: a perspective on their roles in epithelial homeostasis and remodeling. Dis Model Mech. 3, 545-56.

Sahoo, D.H., D. Karnak, T..R Gildea, and A.C. Mehta. (2009). Complete tracheal ring. Respiration. 77, 96.

Sala, F.G., P.M. Del Moral, C. Tiozzo, D.A. Alam, D. Warburton, and T. Grikscheit. (2011). FGF10 controls the patterning of the tracheal cartilage rings via Shh. Development.138, 273-82.

Saldaña, J.I., A. Solanki, C.I. Lau, H. Sahni, S. Ross, A.L. Furmanski, M. Ono, G. Holländer, T. Crompton. (2016). Sonic Hedgehog regulates thymic epithelial cell differentiation. J Autoimmun. 68, 86-97.

Schmid, A., J. Sailland, L. Novak, N. Baumlin, N. Fregien, and M. Salathe. (2017). Modulation of Wnt signaling is essential for the differentiation of ciliated epithelial cells in human airways. FEBS Lett. 591, 3493-3506.

Shin, K., J. Lee, N. Guo, J. Kim, A. Lim, L. Qu, I.U. Mysorekar, and P.A. Beachy. (2011). Hedgehog/Wnt feedback supports regenerative proliferation of epithelial stem cells in bladder. Nature. 472, 110-4.

Sinner, D.I., B. Carey, D. Zgherea, K.M. Kaufman, L. Leesman, R.E. Wood, M.J. Rutter, A. de Alarcon, R.G. Elluru, J.B. Harley, et al. (2019). Complete Tracheal Ring Deformity: A Translational Genomics Approach to Pathogenesis. Am J Respir Crit Care Med. 200, 1267-1281. 
Snowball, J., M. Ambalavanan, J. Whitsett, and D, Sinner. (2015). Endodermal Wnt signaling is required for tracheal cartilage formation. Dev Biol. 405, 56-70.

Sountoulidis, A., A. Liontos, H.P. Nguyen, A.B. Firsova, A. Fysikopoulos, X. Qian, W. Seeger, E. Sundström, M. Nilsson, and C. Samakovlis. (2020). SCRINSHOT enables spatial mapping of cell states in tissue sections with single-cell resolution. PLoS Biol. 18, e3000675.

Stauber, M., M. Weidemann, O. Dittrich-Breiholz, K. Lobschat, L. Alten, M. Mai, A. Beckers, M. Kracht, and Gossler, A. (2017). Identification of FOXJ1 effectors during ciliogenesis in the foetal respiratory epithelium and embryonic left-right organiser of the mouse. Dev Biol. 423, 170-188.

Thayer, S.P., M.P. di Magliano, P.W. Heiser, C.M. Nielsen, D.J. Roberts, G.Y. Lauwers, Y.P. Qi, S. Gysin, C. Fernández-del Castillo, V. Yajnik, et al. (2003). Hedgehog is an early and late mediator of pancreatic cancer tumorigenesis. Nature. 425, 851-6.

Tiozzo, C., De Langhe, S., Yu, M., Londhe, V.A., Carraro, G., Li, M., Li, C., Xing, Y., Anderson, S., Borok, Z., et al. (2009). Deletion of Pten expands lung epithelial progenitor pools and confers resistance to airway injury. Am J Respir Crit Care Med. 180, 701-12.

van Dop, W.A., S.L. Rosekrans, A. Uhmann, V. Jaks, G.J. Offerhaus, M.A. van den Bergh Weerman, M. Kasper, J. Heijmans, J.C. Hardwick, H.W. Verspaget, et al. (2013). Hedgehog signalling stimulates precursor cell accumulation and impairs epithelial maturation in the murine oesophagus. Gut. 62, 348-57.

van den Brink, G.R., S.A. Bleuming, J.C. Hardwick, B.L. Schepman, G.J. Offerhaus, J.J. Keller, C. Nielsen, W. Gaffield, S.J. van Deventer, D.J. Roberts, et al. (2004). Indian Hedgehog is an antagonist of Wnt signaling in colonic epithelial cell differentiation. Nat Genet. 36, 277-82.

Volckaert, T., Campbell, A., Dill, E., Li, Changgong., Minoo, P., De Langhe, S. (2013). Localized Fgf10 expression is not required for lung branching morphogenesis but prevents differentiation of epithelial progenitors. Development. 140, 3731-3742.

Wang, C., M. Cassandras, and T. Peng. (2019). The Role of Hedgehog Signaling in Adult Lung Regeneration and Maintenance. J Dev Biol. 7, pii: E14.

Wang, C., N.S.R. de Mochel, S.A. Christenson, M. Cassandras, R. Moon, A.N. Brumwell, L.E. Byrnes, A. Li, Y. Yokosaki, and P. Shan. (2018). Expansion of hedgehog disrupts mesenchymal identity and induces emphysema phenotype. J Clin Invest.128, 4343-4358.

Watkins, D.N., D.M. Berman, S.G. Burkholder, B. Wang, P.A. Beachy, and S.B. Baylin. (2003). Hedgehog signalling within airway epithelial progenitors and in small-cell lung cancer. Nature. 422, 313-7.

Weaver, M., L. Batts, and B.L. Hogan. (2003). Tissue interactions pattern the mesenchyme of the embryonic mouse lung. Dev Biol. 258, 169-84.

Xu, Q., Tam, M. and Anderson SA. (2008). Fate mapping Nkx2.1-lineage cells in the mouse telencephalon. J Comp Neurol. 506, 16-29. 


\section{Yin, W., H.T. Kim, S. Wang, F. Gunawan, L. Wang, K. Kishimoto, H. Zhong, D.}

Roman, J. Preussner, S. Guenther, et al. (2018). The potassium channel KCNJ13 is essential for smooth muscle cytoskeletal organization during mouse tracheal tubulogenesis. Nat Commun. 9, 2815. 


\section{ACKNOWLEDGEMENTS}

We thank, Radhan Ramadass, Anoop Cherian and Yu Hsuan Carol Yang for imaging assistance, Ramesh-Kumar Krishnan, Thomas Sontag, Sigrid Einemann for discussions, and/or assistance.

\section{AUTHOR CONTRIBUTIONS}

W.Y. and C.S. conceived the project, designed experiments and analyzed data; W.Y., A.L., L.M., J.K., M.G., X.L., C.L., H.W. and A.F. contributed to experiments and data analysis; J.K., C.R., A.G. prepared primary human bronchial epithelial (HBE) cells; A.S. contributed to data analysis. C.S., W.S. and D.Y.R.S. provided infrastructure and contributed to data analysis; W.Y., A.L. and C.S. wrote the manuscript. All authors commented on the manuscript. Funding for this study was provided by the National Natural Science Foundation of China (81970019), Open Project of State Key Laboratory of Respiratory Disease (SKLRDOP-202110), Guangdong Key Research and Development Project (2020B1111330001), and ZHONGNANSHAN MEDICAL FOUNDATION OF GUANGDONG PROVINCE (ZNSA2020001) to W.Y., the German Research Foundation (DFG), grant KFO309 (project number 284237345) and the Swedish Cancer Society to C.S. and the Max Planck Society to D.Y.R.S and C.S.

\section{COMPETING INTERESTS}

The authors declare no competing interests. 


\section{Figure Legends}

FIGURE 1. $N k x 2.1^{C r e} ; S_{h} h^{f l o x / f l o x}$ mice exhibit fracture of the tracheal cartilage, pulmonary hemorrhage and cystic lungs. (a-b) mRNA in situ detection of Cdhl (green), Trp63 (wine), Shh (magenta), Smo (yellow), Ptchl (sand), Ptch2 (blue), Hhip (pale-green), Gli1 (orange), Gli2 (cyan) and Gli3 (olive) expression and DAPI staining (grey) of longitudinal sections of WT tracheae at different developmental stages. The dashed insert square in the large image indicates the area enlarged and rotated in the right side of the panels. Dashed lines in small images on the right side indicate the border between the tracheal epithelium and mesenchyme. (c) Quantification of the percentage of positive cells within each cell state that express Hh signaling components. (d) Quantification of the percentage of positive cells that express $\mathrm{Hh}$ signaling components. Number of cells at E12.5=239, $\mathrm{E} 13.5=455, \mathrm{E} 14.5=1232, \mathrm{E} 15.5=931, \mathrm{E} 16.5=365, \mathrm{E} 18.5=286$. (e) Representative gross morphology of P0 control $(n=6)$ and ShhCKO mutants $(n=6)$. (f) Quantification of P0 control $(n=6)$ and ShhCKO mutant $(n=6)$ respiratory rate. (g) Representative images of transverse sections of tracheae stained with alcian blue and nuclear fast red from P0 control $(n=5)$ and ShhCKO mutants $(n=5)$. (h) Quantification of P0 control $(n=5)$ and ShhCKO mutant ( $\mathrm{n}=5)$ tracheal lumen area. (i) Representative images of ventral views of whole-mount tracheae stained with alcian blue from P0 control $(n=6)$ and ShhCKO mutants $(n=6)$. Arrows point to tracheal cartilage rings. (j) Quantification of the number of intact tracheal cartilage rings from P0 control $(n=6)$ and ShhCKO mutants $(n=6)$. (k) Representative images of ventral views of the trachea and lungs from P0 control $(n=6)$ and ShhCKO mutants $(n=6)$. White arrows point to pulmonary cysts. Blue arrows point to blood spots. (l) Percentage of lungs with hemorrhage. (m) Percentage of lungs with cysts. Scale bars: 2000 $\mu \mathrm{m}(\mathbf{k}), 1000 \mu \mathrm{m}(\mathbf{e}, \mathbf{i}), 400 \mu \mathrm{m}(\mathbf{g}), 100 \mu \mathrm{m}$ (tracheal large images in $\mathbf{a}, \mathbf{b}), 10 \mu \mathrm{m}$ (tracheal small images in $\mathbf{a}, \mathbf{b})$. Unpaired Student's $t$-test, mean \pm s.d. $(\mathbf{f}, \mathbf{h}, \mathbf{j}, \mathbf{l}, \mathbf{m})$. E, epithelium; M, Mesenchyme; Shh, Sonic Hedgehog; Smo, Smoothened; ShhCKO, Sonic Hedgehog conditional knockout.

\section{FIGURE 2. $N k x 2.1^{C r e} ; S h h^{f l o x / f l o x}$ mice exhibit defects in tracheal epithelial cell} proliferation and differentiation. (a) Immunostaining for FOXJ1 (red), NKX2.1 (green) and DAPI staining (blue) of longitudinal sections of E18.5 control $(\mathrm{n}=6)$ and $\operatorname{ShhCKO}(\mathrm{n}=6)$ tracheae. (b) Quantification of the relative number of FOXJ1 ${ }^{+}$cells in the tracheal epithelium in E18.5 control $(\mathrm{n}=6)$ and $\operatorname{ShhCKO}(\mathrm{n}=6)$ mice. (c) RT-qPCR analysis of Foxj1, Tubb4b, Scgblal and Foxpl mRNA levels in E18.5 control $(\mathrm{n}=5)$ and ShhCKO $(n=5)$ tracheae. (d) Immunostaining for acetylated alpha-tubulin (red) and DAPI staining (blue) of longitudinal sections of E18.5 control $(n=6)$ and ShhCKO $(n=6)$ tracheae. (e) Quantification of the relative number of acetylated alpha-tubulin ${ }^{+}$cells in the tracheal epithelium in E18.5 control $(n=6)$ and ShhCKO (n=6) mice. (f) Immunostaining for SCGB1A1 (red), NKX2.1 (green) and DAPI staining (blue) of longitudinal sections of E18.5 control $(\mathrm{n}=6)$ and $\operatorname{ShhCKO}(\mathrm{n}=6)$ tracheae. (g) Quantification of the relative number of SCGB1A1 ${ }^{+}$cells in the tracheal epithelium in E18.5 control $(\mathrm{n}=6)$ and $\operatorname{ShhCKO}(\mathrm{n}=6)$ mice. (h) Immunostaining for CDH1 (red), Ki67 (green) and DAPI staining (blue) of longitudinal sections of E18.5 control (n=6) and $\operatorname{ShhCKO}(\mathrm{n}=6)$ tracheae. (i) Ratio of $\mathrm{CDH} 1^{+}$cells that are $\mathrm{Ki}^{+} 7^{+}$. (j) EdU fluorescence (red), immunostaining for CDH1 (green) and DAPI staining (blue) of longitudinal sections of 
E18.5 control $(\mathrm{n}=6)$ and $\operatorname{ShhCKO}(\mathrm{n}=6)$ tracheae. (k) Ratio of $\mathrm{CDH}^{+}$cells that are $\mathrm{EdU}^{+}$. (l) Immunostaining for SCGB1A1 (red), Ki67 (green) and DAPI staining (blue) of longitudinal sections of E18.5 control $(n=6)$ and $\operatorname{ShhCKO}(\mathrm{n}=6)$ tracheae. $(\mathbf{m})$ Ratio of SCGB1A1 ${ }^{+}$cells that are Ki67 $7^{+}$Scale bars: $20 \mu \mathrm{m}$. Unpaired Student's $t$-test, mean \pm s.d.

\section{FIGURE 3. Smo mediates Hh-signaling in tracheal epithelial cells and controls their} differentiation and proliferation. (a) Immunostaining for FOXJ1 (red), NKX2.1 (green) and DAPI staining (blue) of longitudinal sections of E18.5 control (n=6) and SmoCKO $(\mathrm{n}=6)$ tracheae. (b) Quantification of the relative number of FOXJ1 ${ }^{+}$cells in the tracheal epithelium in E18.5 control $(\mathrm{n}=6)$ and $\operatorname{SmoCKO}(\mathrm{n}=6)$ mice. (c) RT-qPCR analysis of Foxj1, Tubb4b and Scgblal mRNA levels in E18.5 control $(\mathrm{n}=5)$ and $\operatorname{SmoCKO}(n=5)$ tracheae. (d) Immunostaining for acetylated alpha-tubulin (red), NKX2.1 (green) and DAPI staining (blue) of longitudinal sections of E18.5 control $(n=6)$ and SmoCKO $(n=6)$ tracheae. (e) Quantification of the relative number of acetylated alpha-tubulin ${ }^{+}$cells in the tracheal epithelium in E18.5 control ( $\mathrm{n}=6)$ and $\operatorname{SmoCKO}(\mathrm{n}=6)$ mice. (f) Immunostaining for SCGB1A1 (red), NKX2.1 (green) and DAPI staining (blue) of longitudinal sections of E18.5 control $(\mathrm{n}=6)$ and $\operatorname{SmoCKO}(\mathrm{n}=6)$ tracheae. (g) Quantification of the relative number of $\mathrm{SCGB} 1 \mathrm{~A} 1^{+}$cells in the tracheal epithelium in E18.5 control $(\mathrm{n}=6)$ and $\operatorname{SmoCKO}(\mathrm{n}=6)$ mice. (h) EdU fluorescence (red), immunostaining for CDH1 (green) and DAPI staining (blue) of longitudinal sections of E18.5 control $(n=6)$ and SmoCKO $(n=6)$ tracheae after a $21 \mathrm{~h} 10 \mu \mathrm{M}$ EdU treatment. (i) Ratio of $\mathrm{CDH}^{+}$cells that are $\mathrm{EdU}^{+}$. (j) Immunostaining for acetylated alpha-tubulin (red) and DAPI staining (blue) of longitudinal sections of P9 control $(\mathrm{n}=4)$ and $N k x 2.1^{C r e} ; R 26^{\operatorname{SmoM} 2}(\mathrm{n}=4)$ tracheae. (k) Quantification of the relative number of acetylated alpha-tubulin $^{+}$cells in the tracheal epithelium in P9 control $(\mathrm{n}=4)$ and $N k x 2.1^{C r e} ; R 26^{S m o M 2}(\mathrm{n}=4)$ mice. (l) Immunostaining for SCGB1A1 (red) and DAPI staining (blue) of longitudinal sections of P9 control $(\mathrm{n}=4)$ and $N k x 2.1^{C r e} ; R 26^{\operatorname{SmoM2}}(\mathrm{n}=4)$ tracheae. (m) Quantification of the relative number of SCGB1A1 ${ }^{+}$cells in the tracheal epithelium in P9 control $(\mathrm{n}=4)$ and $N k x 2.1^{C r e} ; R 26^{S m o M 2}(\mathrm{n}=4)$ mice. Scale bars: $20 \mu \mathrm{m}$. Unpaired Student's $t$ test, mean \pm s.d.

FIGURE 4. Hh signaling regulates HBE cell differentiation. (a-d) RT-qPCR analysis of mRNA levels of Hh-signaling components in ALI-cultured HBE cells ( $\mathrm{n}=6$ per stage). (a) $S H H$, (b) SMO, (c) GLI1 (d) GLI2. (e) Immunostaining for FOXJ1 (red), MUC5AC (green) and DAPI staining (blue) in HBE cells at the ALI after 9 days of ethanol $(\mathrm{n}=6)$ or $10 \mu \mathrm{M}$ cyclopamine $(\mathrm{n}=6)$ treatment. (f) Quantification of the relative number of $\mathrm{FOXJ} 1^{+}$cells in HBE cells at the ALI after 9 days of ethanol $(n=6)$ or $10 \mu \mathrm{M}$ cyclopamine $(n=6)$ treatment. 2943 and $477 \mathrm{FOXJ}^{+}$cells were analyzed for controls and $10 \mu \mathrm{M}$ cyclopamine treatment respectively. (g) Quantification of the relative number of MUC5AC ${ }^{+}$cells in HBE cells at the ALI after 9 days of ethanol $(n=6)$ or $10 \mu \mathrm{M}$ cyclopamine $(n=6)$ treatment. 3039 and 591 MUC5 $\mathrm{AC}^{+}$cells were analyzed for controls and $10 \mu \mathrm{M}$ cyclopamine treatment respectively. (h) RT-qPCR analysis of FOXJ1, MUC5AC, MUC5B and SPDEF mRNA levels in HBE cells at the ALI after 9 days of ethanol $(n=6)$ or $10 \mu \mathrm{M}$ cyclopamine $(\mathrm{n}=6)$ treatment. (i) Immunostaining for acetylated alpha-tubulin (red), MUC5B (green) and DAPI staining (blue) in HBE cells at the ALI after 9 days of ethanol $(n=6)$ or $10 \mu \mathrm{M}$ cyclopamine $(n=6)$ treatment. (j) Quantification of the relative number of acetylated alpha-tubulin ${ }^{+}$cells in $\mathrm{HBE}$ 
cells at the ALI after 9 days of ethanol $(n=6)$ or $10 \mu \mathrm{M}$ cyclopamine $(n=6)$ treatment. 2670 and 312 acetylated alpha-tubulin ${ }^{+}$cells were analyzed for controls and $10 \mu \mathrm{M}$ cyclopamine treatment respectively. (k) Quantification of the relative number of $\mathrm{MUC} \mathrm{B}^{+}$cells in $\mathrm{HBE}$ cells at the ALI after 9 days of ethanol $(n=6)$ or $10 \mu \mathrm{M}$ cyclopamine $(n=6)$ treatment. 5379

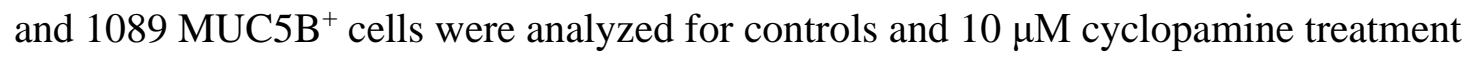
respectively. (l) Immunostaining for FOXJ1 (red), MUC5AC (green) and DAPI staining (blue) in HBE cells at the ALI after 9 days of $\mathrm{ddH}_{2} \mathrm{O}(\mathrm{n}=6)$ or $100 \mathrm{ng} / \mathrm{ml} \mathrm{H-SHH}(\mathrm{n}=6)$ treatment. (m) Quantification of the relative number of FOXJ1+ cells in HBE cells at the ALI after 9 days of $\mathrm{ddH}_{2} \mathrm{O}(\mathrm{n}=6)$ or $100 \mathrm{ng} / \mathrm{ml} \mathrm{H}-\mathrm{SHH}(\mathrm{n}=6)$ treatment. 2685 and $5007 \mathrm{FOXJ} 1^{+}$ cells were analyzed for controls and $100 \mathrm{ng} / \mathrm{ml} \mathrm{H}-\mathrm{SHH}$ treatment respectively. (n) Quantification of the relative number of MUC5AC $\mathrm{AC}^{+}$cells in $\mathrm{HBE}$ cells at the ALI after 9 days of $\mathrm{ddH}_{2} \mathrm{O}(\mathrm{n}=6)$ or $100 \mathrm{ng} / \mathrm{ml} \mathrm{H-SHH}(\mathrm{n}=6)$ treatment. 2838 and $3561 \mathrm{MUC}^{2} \mathrm{AC}^{+}$cells were analyzed for controls and $100 \mathrm{ng} / \mathrm{ml} \mathrm{H}-\mathrm{SHH}$ treatment respectively. (o) RT-qPCR analysis of FOXJ1, MUC5AC mRNA levels in HBE cells at the ALI after 9 days of $\mathrm{ddH}_{2} \mathrm{O}$ $(\mathrm{n}=6)$ or $100 \mathrm{ng} / \mathrm{ml} \mathrm{H-SHH}(\mathrm{n}=6)$ treatment. Scale bars: $100 \mu \mathrm{m}$. Unpaired Student's $t$-test, mean \pm s.d. HBE: human bronchial epithelial; H-SHH: recombinant human SHH.

FIGURE 5. Hh signaling regulates HBE cell proliferation. (a) Timeline for EdU, BrdU and cyclopamine administration. (b) Immunostaining for Ki67 (violet), BrdU (green) and EdU fluorescence (red) in HBE cells at the ALI after ethanol $(n=6)$ or $10 \mu \mathrm{M}$ cyclopamine $(n=6)$ treatment at day 3. (c) Immunostaining for Ki67 (violet), BrdU (green) and EdU fluorescence (red) in HBE cells at the ALI after ethanol $(n=6)$ or $10 \mu \mathrm{M}$ cyclopamine $(n=6)$ treatment at day 5. (d) Immunostaining for Ki67 (violet), BrdU (green) and EdU fluorescence (red) in HBE cells at the ALI after ethanol $(n=6)$ or $10 \mu \mathrm{M}$ cyclopamine $(n=6)$ treatment at day 7. (e) Ratio of BrdU ${ }^{+}$cells to EdU ${ }^{+}$cells at day 3. 1143 and $210 \mathrm{BrdU}^{+}$cells were analyzed for controls and $10 \mu \mathrm{M}$ cyclopamine treatment respectively. (f) Ratio of $\mathrm{Ki6} 7^{+}$cells to $\mathrm{EdU}^{+}$cells at day 3. 1278 and $225 \mathrm{Ki}^{+} 7^{+}$cells were analyzed for controls and $10 \mu \mathrm{M}$ cyclopamine treatment respectively. (g) Ratio of $\mathrm{BrdU}^{+}$cells to EdU ${ }^{+}$cells at day 5. 1491 and $408 \mathrm{BrdU}^{+}$cells were analyzed for controls and $10 \mu \mathrm{M}$ cyclopamine treatment respectively. (h) Ratio of $\mathrm{Ki}^{+}$cells to EdU ${ }^{+}$cells at day 5. 1479 and $432 \mathrm{Ki}^{+} 7^{+}$cells were analyzed for controls and $10 \mu \mathrm{M}$ cyclopamine treatment respectively. (i) Ratio of $\mathrm{BrdU}^{+}$cells to $\mathrm{EdU}^{+}$cells at day 7. 1467 and $375 \mathrm{BrdU}^{+}$cells were analyzed for controls and $10 \mu \mathrm{M}$ cyclopamine treatment. (j) Ratio of $\mathrm{Ki}^{+}$cells to $\mathrm{EdU}^{+}$cells at day 7.1611 and $429 \mathrm{Ki}^{+}$ cells were analyzed for controls and $10 \mu \mathrm{M}$ cyclopamine treatment respectively. Scale bars: $100 \mu \mathrm{m}$. Unpaired Student's $t$-test, mean \pm s.d. 
bioRxiv preprint doi: https://doi.org/10.1101/2022.01.13.476169; this version posted January 14,2022 . The copyright holder for this

a
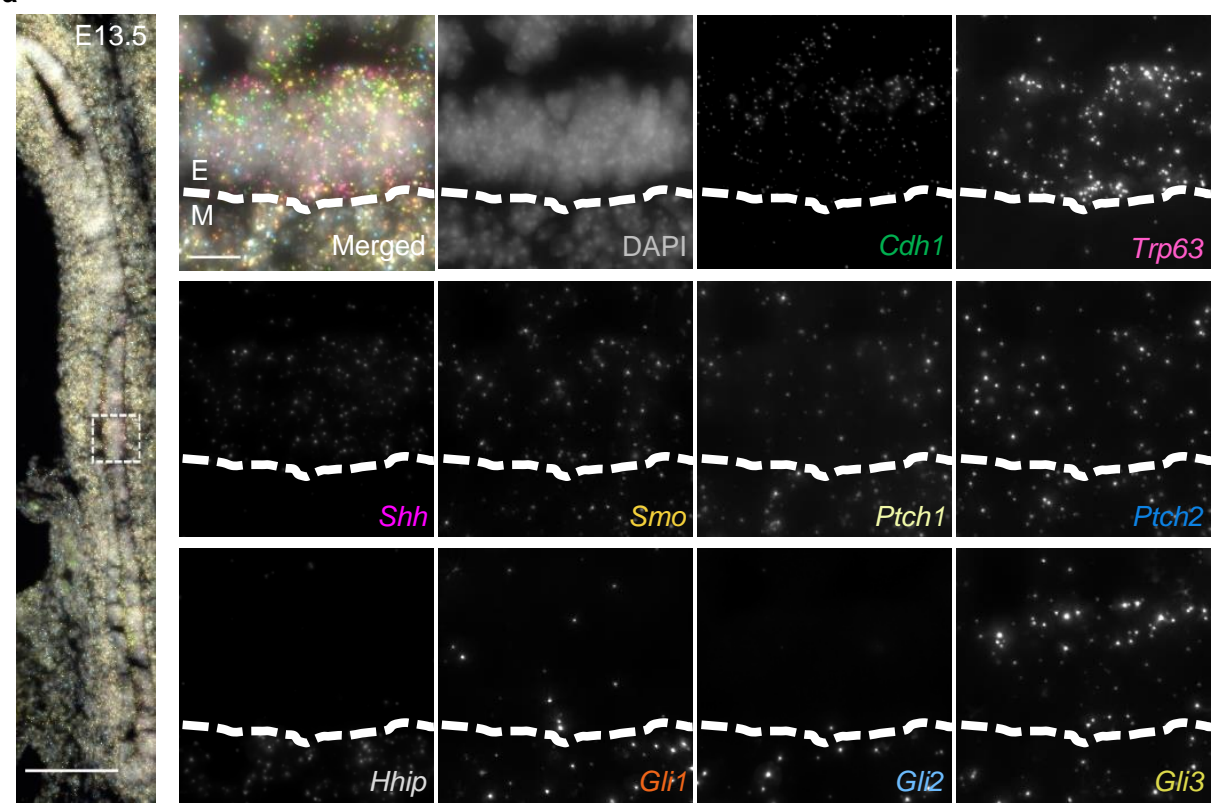

b
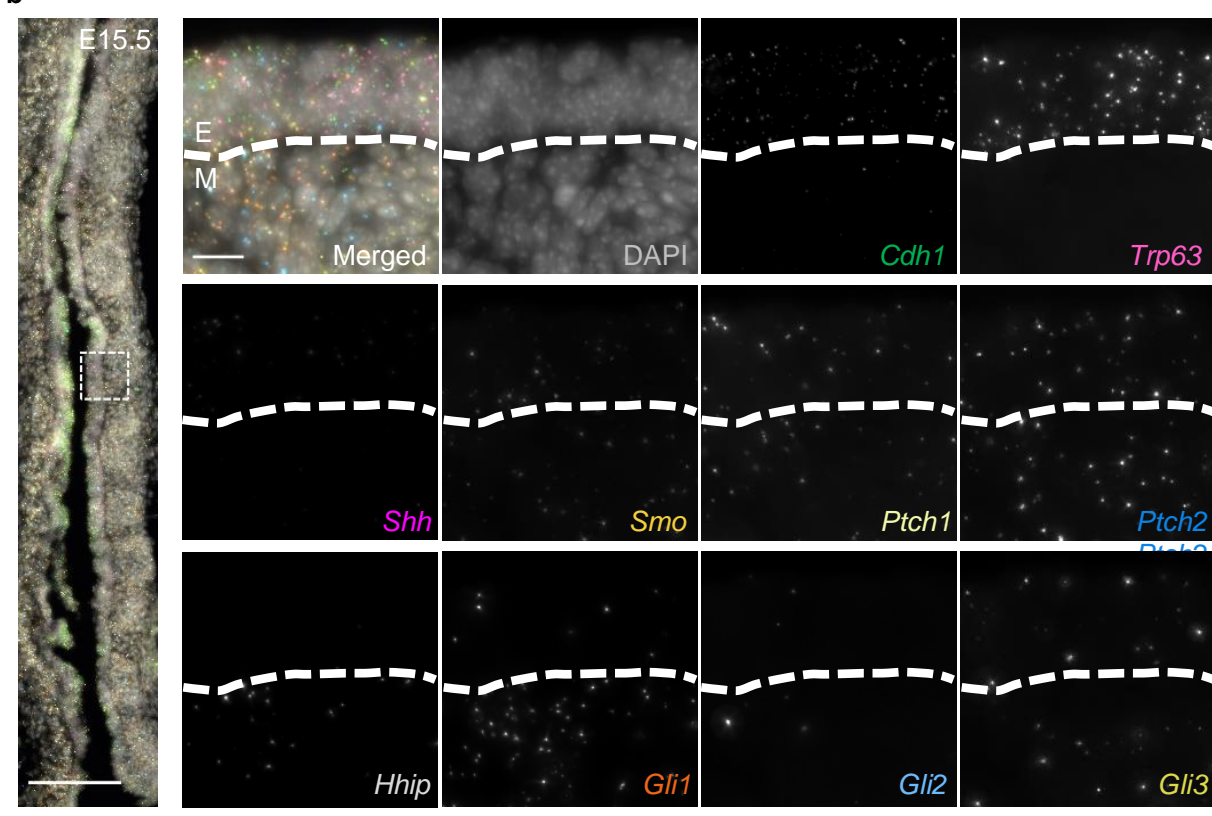

Hhip
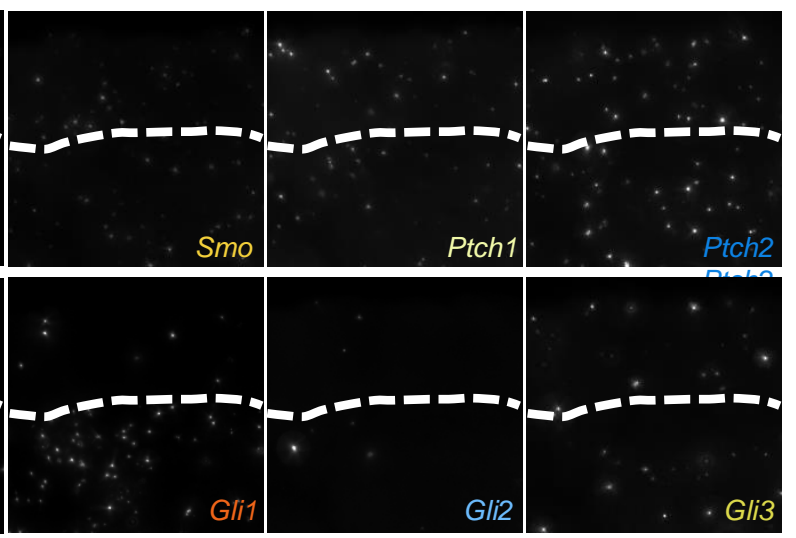

c

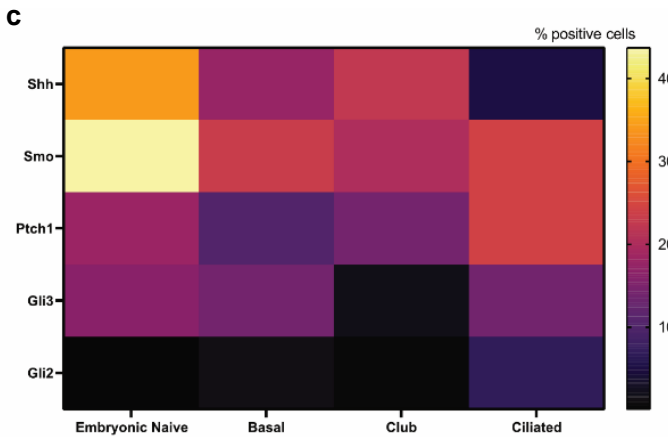

d

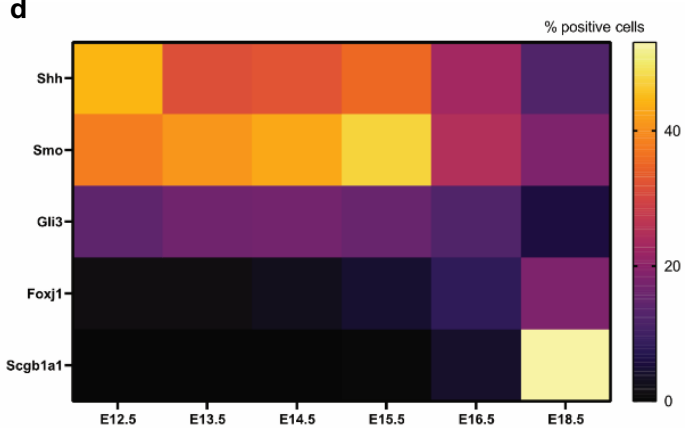

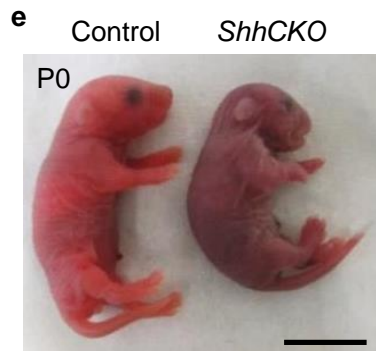

\section{f}

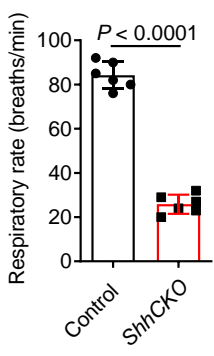

g

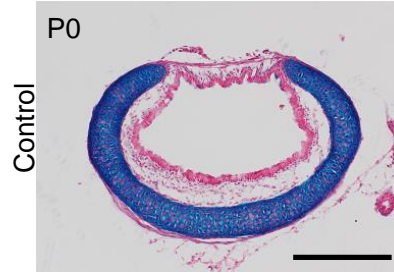

h
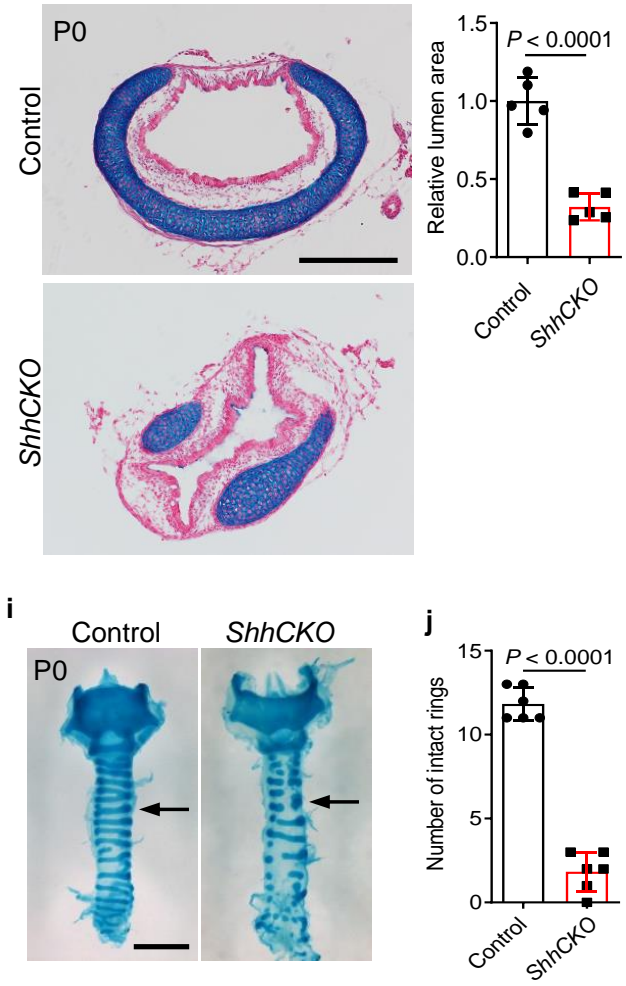

k

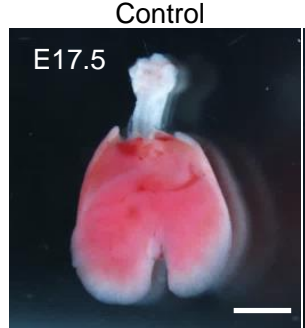

ShhCKO

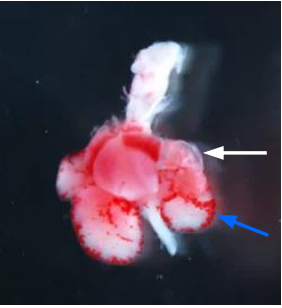

m

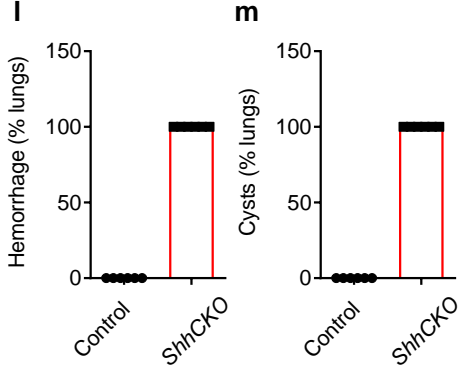



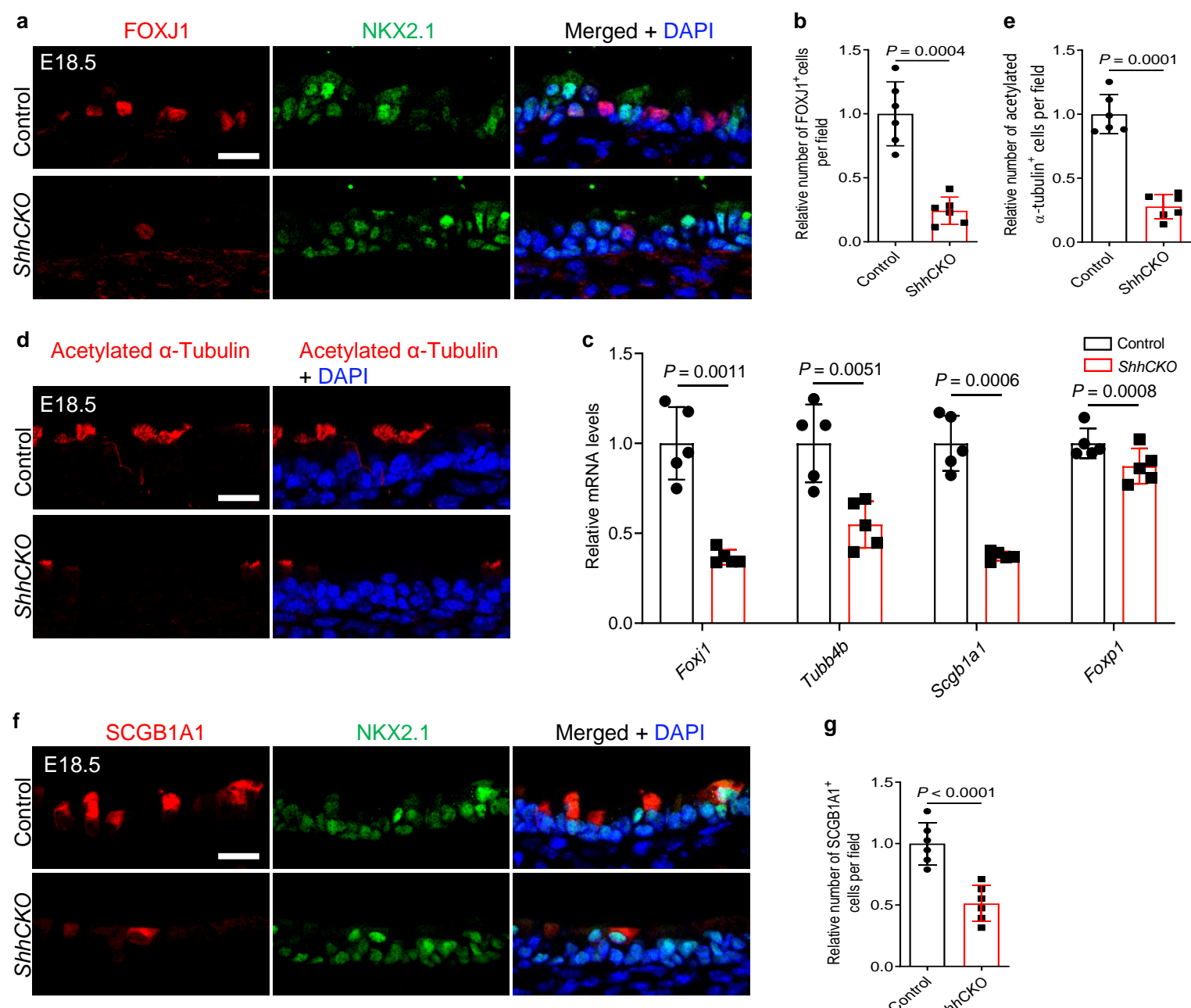

NKX2.1

h
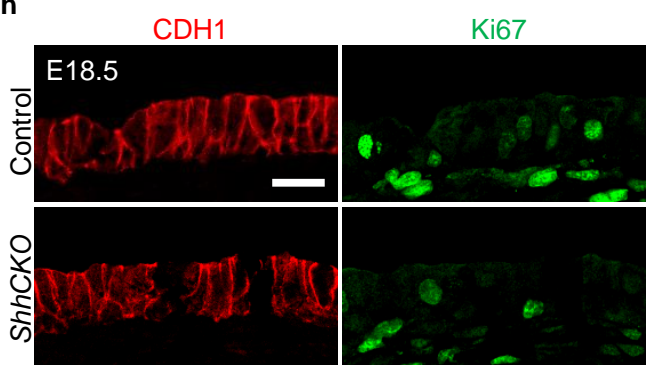

Merged + DAPI
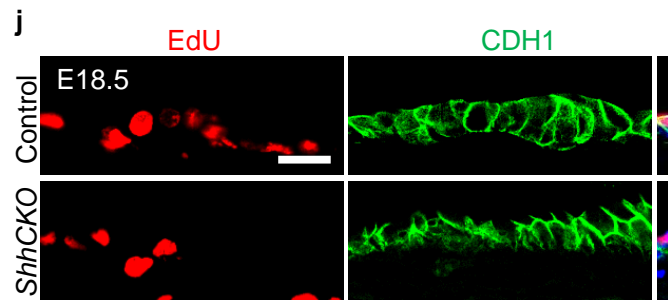

Merged + DAPI
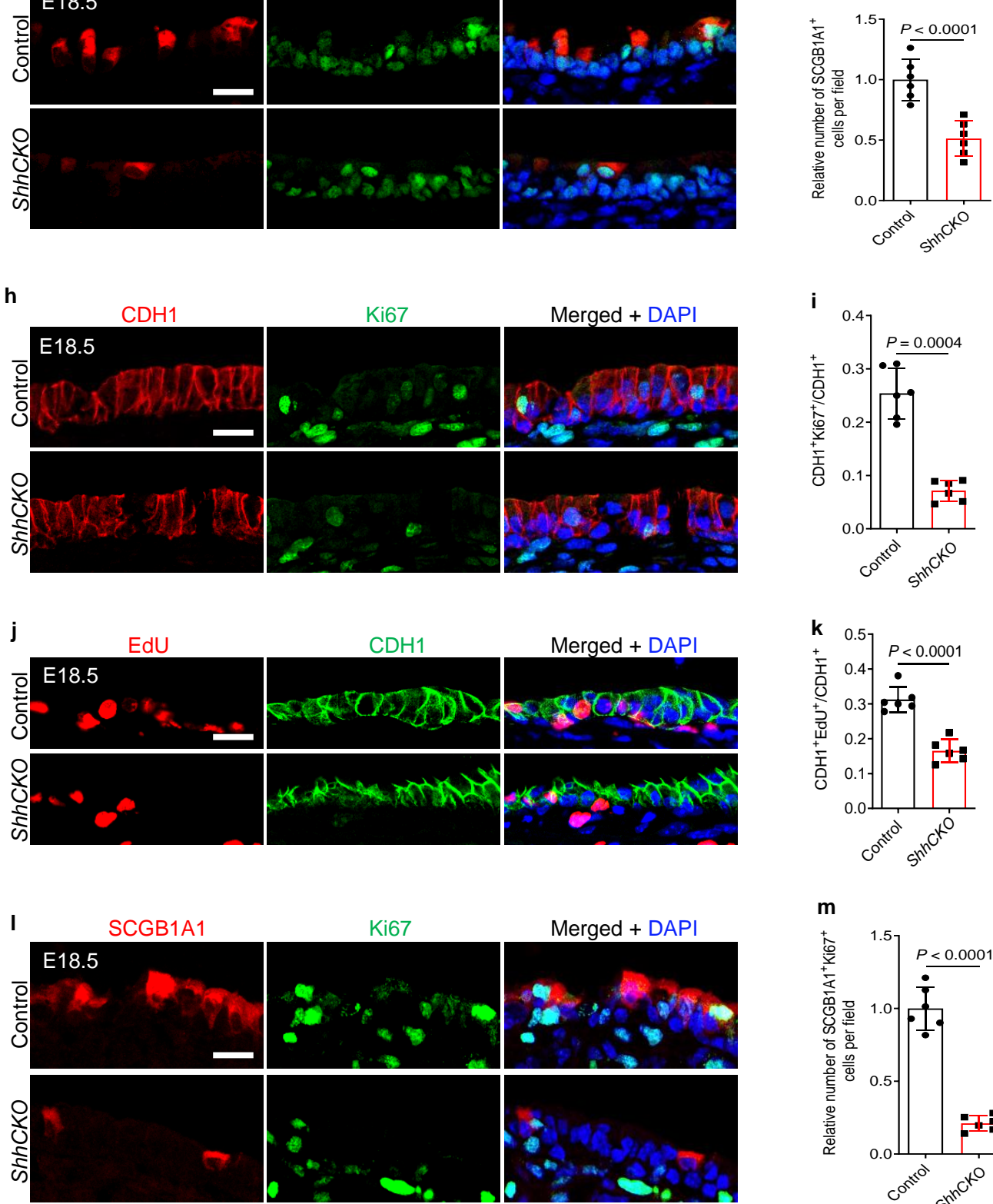

Yin et al., Fig. 2.

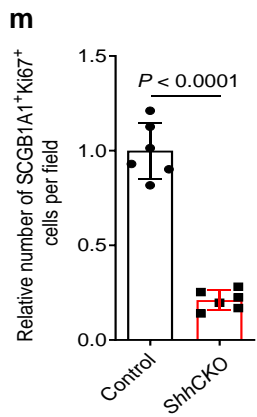



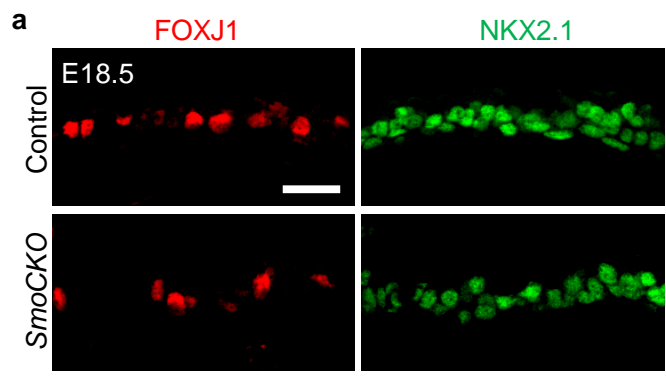

d Acetylated $\alpha$-Tubulin
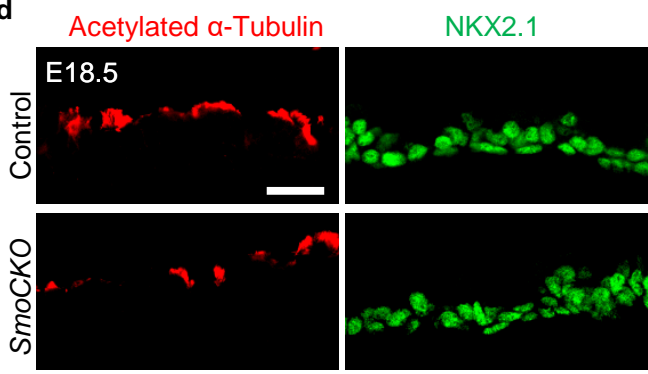

f
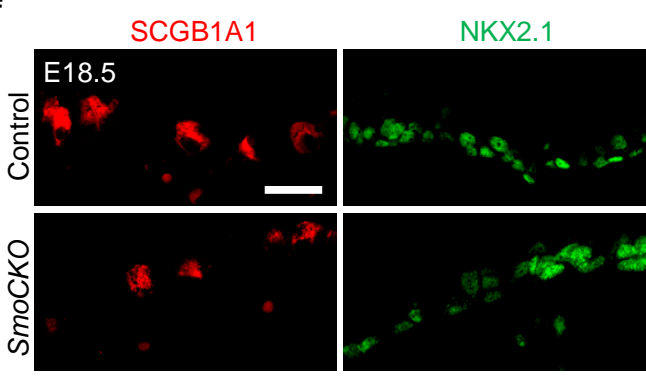

h
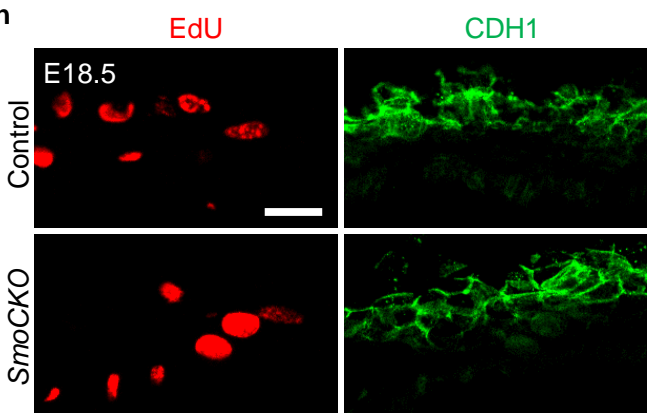

j

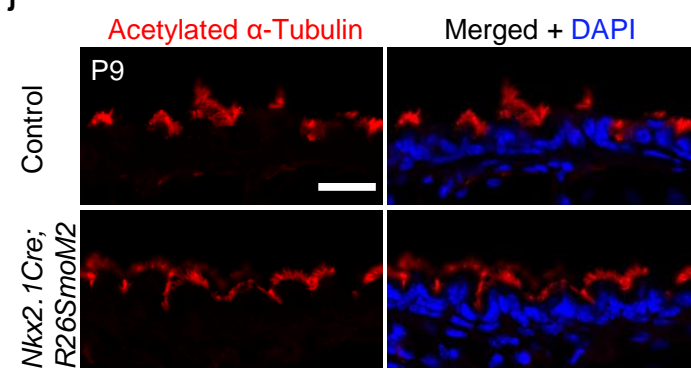

Merged + DAPI

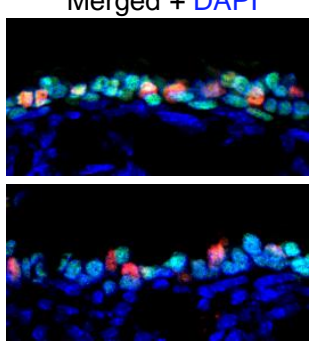

Merged + DAPI

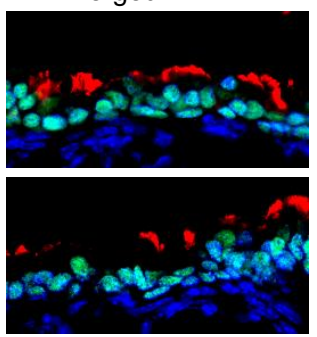

Merged + DAPI

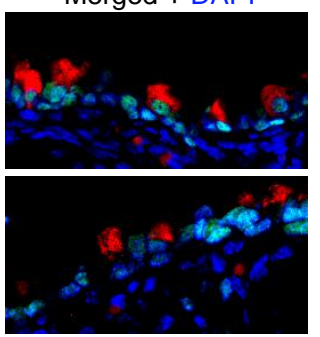

Merged + DAPI

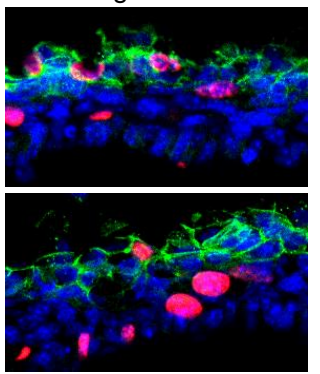

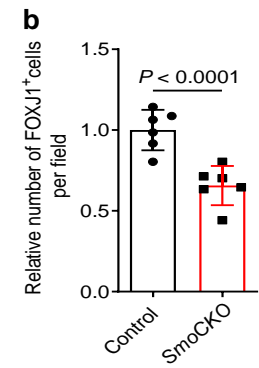
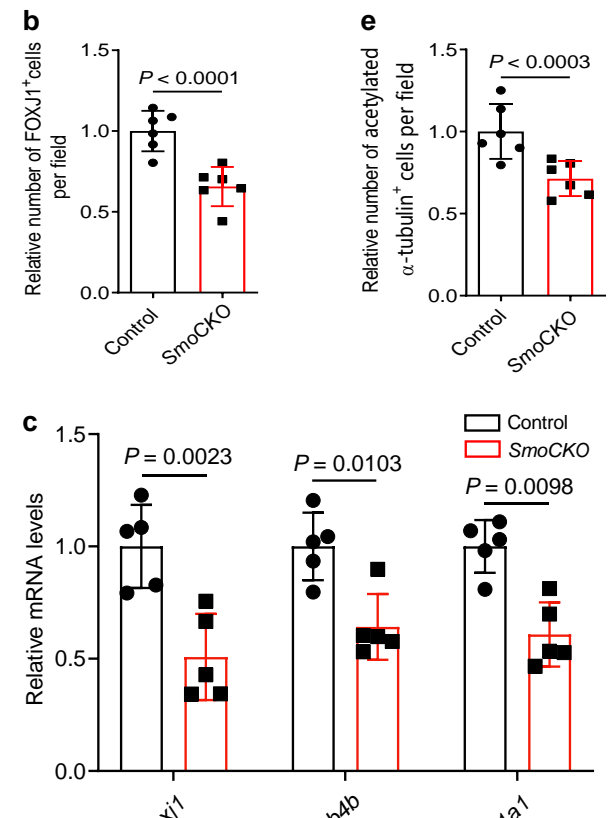

$10^{100^{10}}$
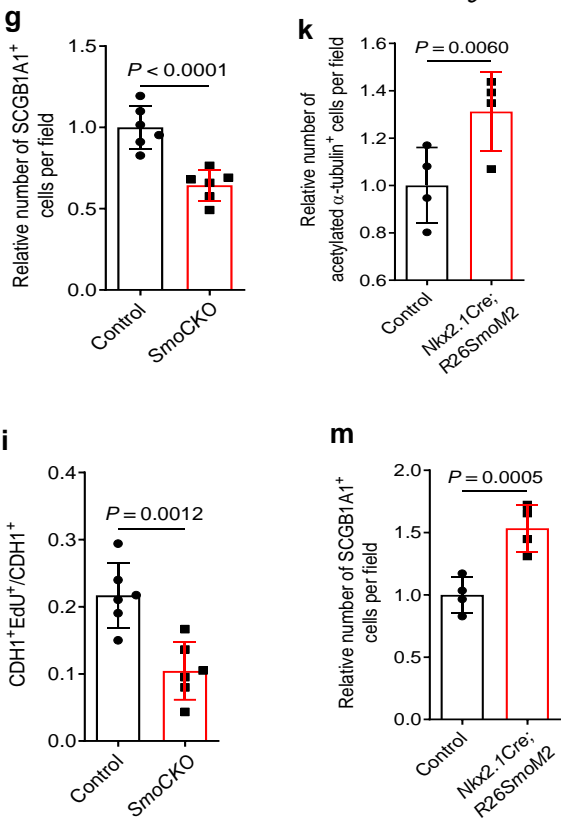

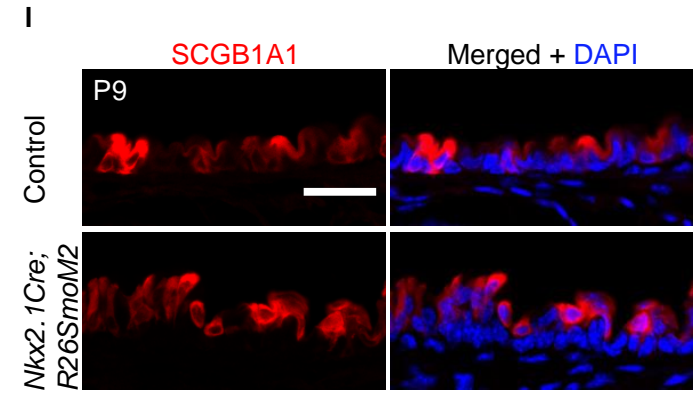

Yin et al., Fig. 3. 
bioRxiv preprint doi: https://doi org/10.1101/2022.01.13.476169; this version posted January 14, 2022. The copyright holder for this preprint (which was not certified by peer review) is the author/funder. All rights reserved. No reuse allowed without permission.

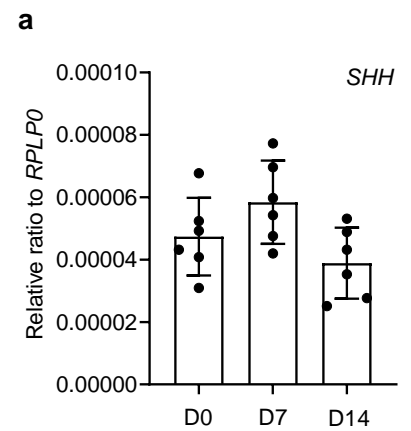

b

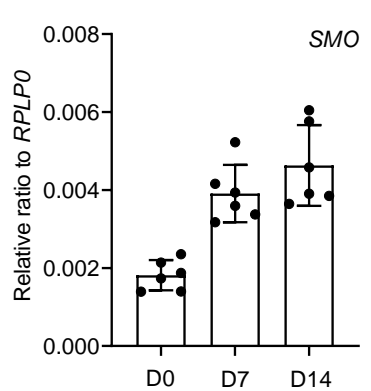

c

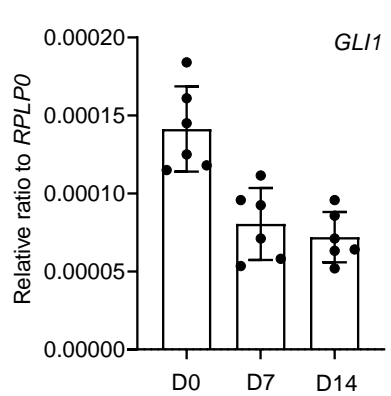

d

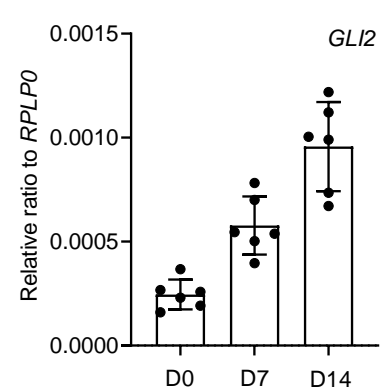

e

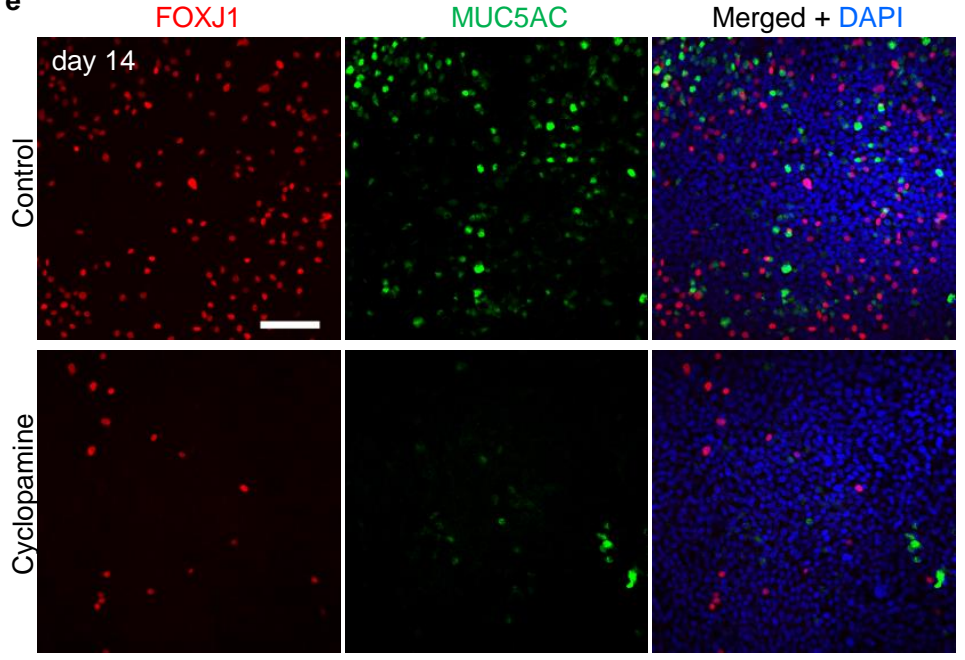

i Acetylated $\alpha$-Tubulin

MUC5B

Merged + DAPI
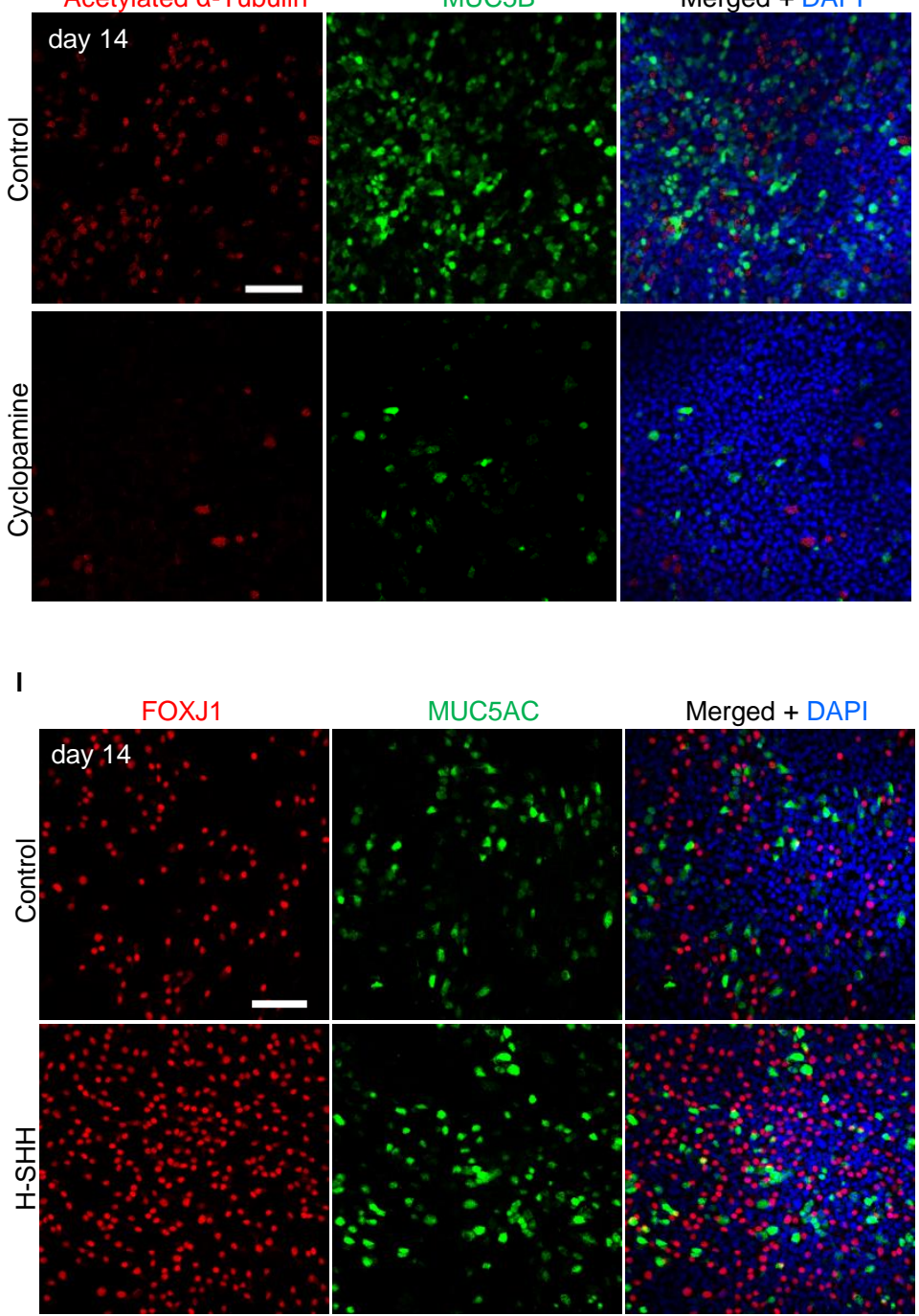
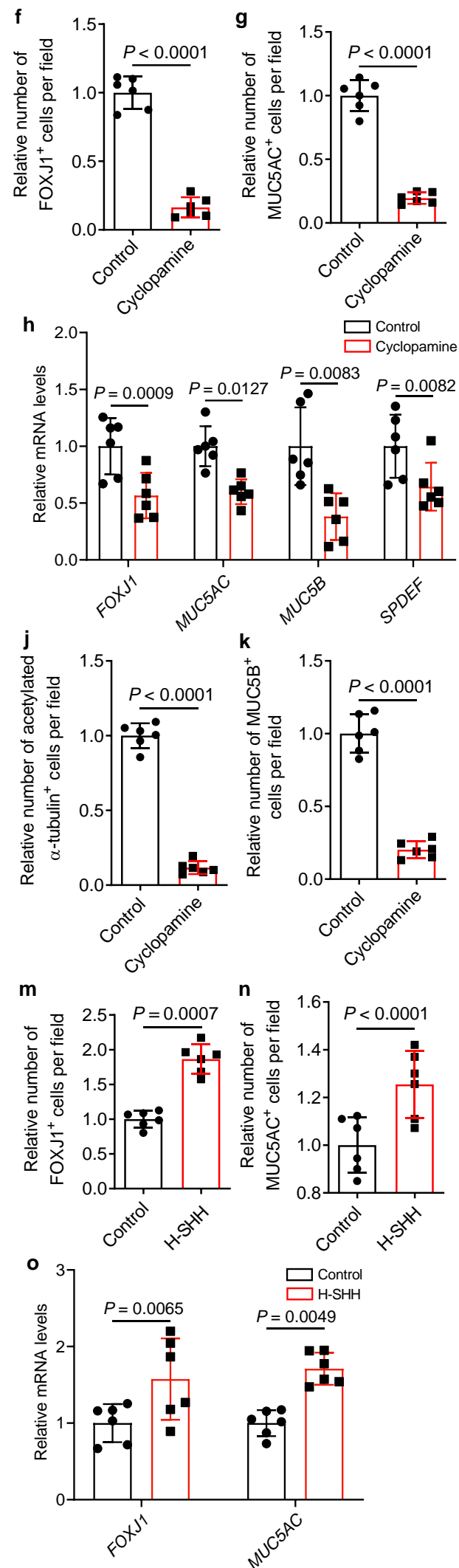

Yin et al., Fig. 4. 

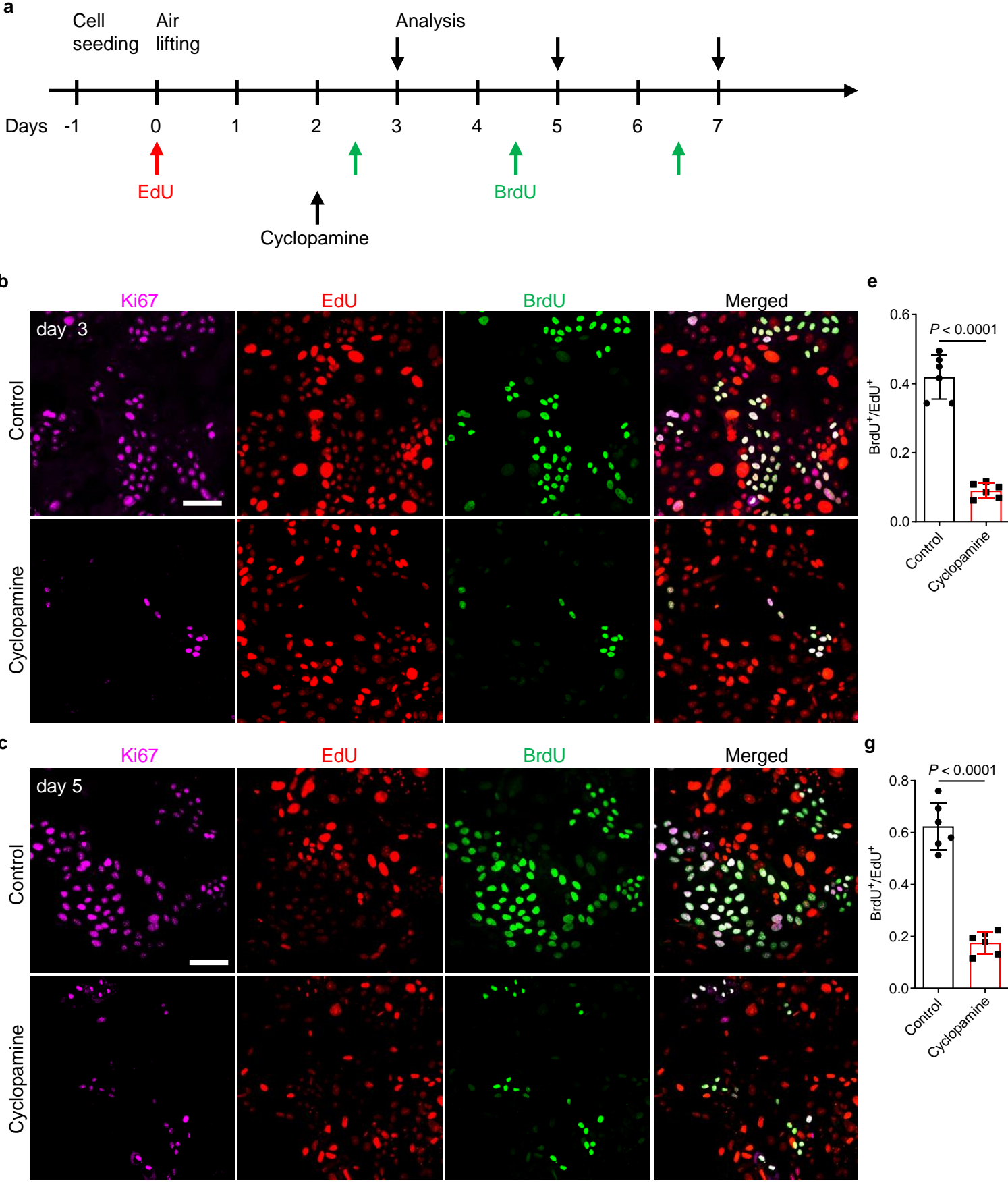

h
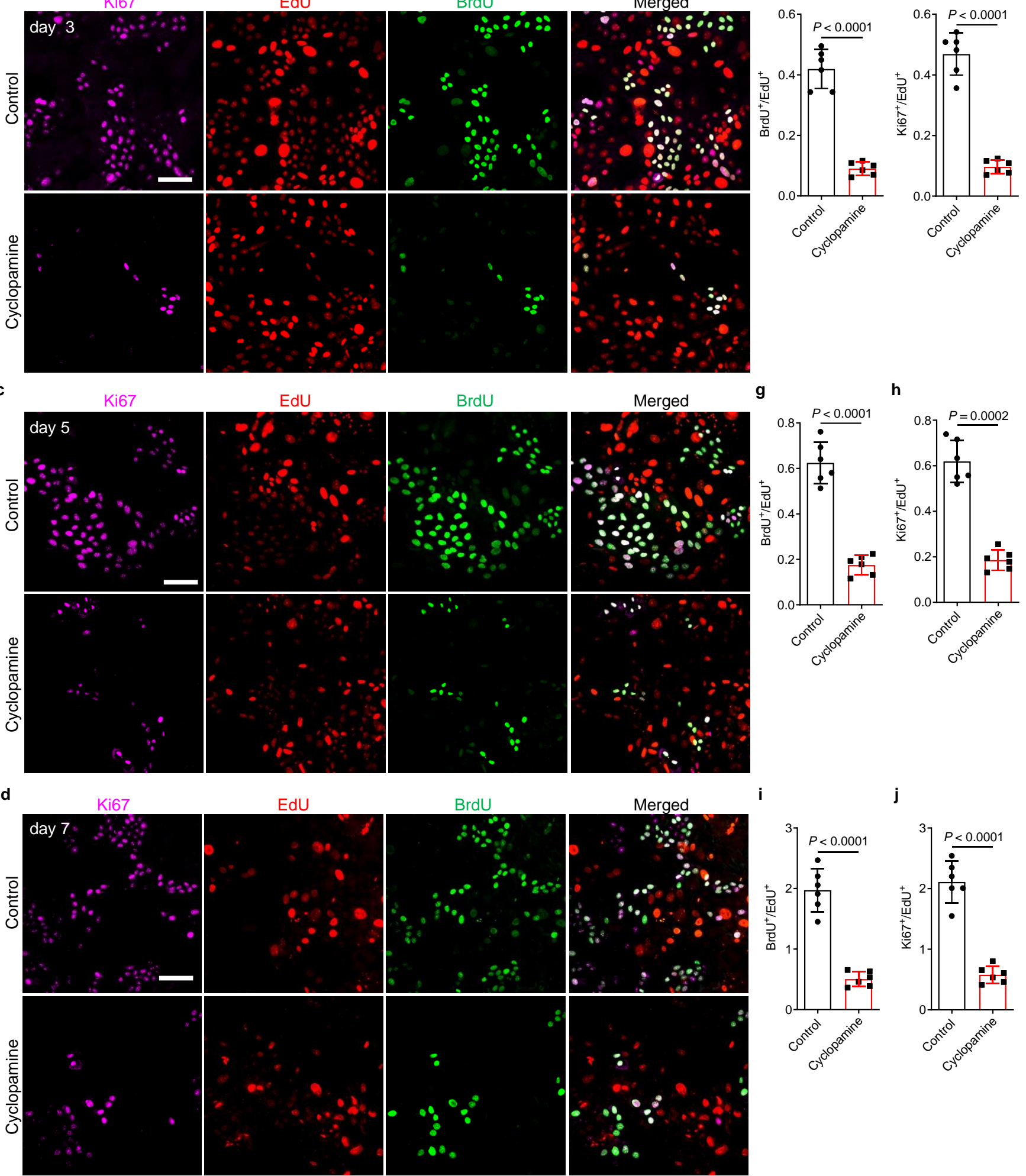

Yin et al., Fig. 5. 